\title{
Presupuesto Participativo: una tipología para superar los límites de las definiciones demasiado amplias o restrictivas ${ }^{1}$
}

\author{
Valdemir Pires \\ Universidade Estadual Paulista, Araraquara SP Brasil \\ Carmen Pineda \\ Consultora de Administraciones Públicas
}

\begin{abstract}
Sumario: INTRODUCCIÓN. - 1. Elementos para una definición del Presupuesto Participativo a partir de su origen en Brasil - el Presupuesto Participativo como proceso. - 2. Elementos para una definición que se produce por la evolución del Presupuesto Participativo en América Latina - el Presupuesto Participativo como proceso histórico. - 3. El Presupuesto participativo en otros continentes: riesgos y oportunidades de definiciones amplias. -4 . Definiciones a partir de las fracturas ideológicas (movimentalismo x gerencialismo) - el Presupuesto Participativo como innovación institucional. - 5. Definiciones adjetivadas - una tipología del Presupuesto Participativo a partir de los objetivos y diseños de las experiencias. 5.1. Tipología de Presupuesto Participativo según el objetivo: transparencia, fiscalización, consulta y deliberación. 5.2. Tipología de Presupuesto Participativo según las fases del proceso presupuestario: elaboración, aprobación, ejecución y evaluación. 5.3. Tipología de Presupuesto Participativo según el objeto de deliberación/consulta o fiscalización: gasto total, gasto en inversión, directrices de políticas públicas, ingresos y tributación. 5.4. Tipología de Presupuesto Participativo según el nivel de gobierno: local, regional o de estado, nacional. 5.5. Tipología de Presupuesto Participativo en lo que respecta a la fuente de poder que lo propone o impone: gobierno nacional, del estado, local, grupo de la sociedad civil local, agencia de desarrollo o financiación. 5.6. Tipología de Presupuesto Participativo según los criterios para la habilitación de los participantes. 5.7. Tipología del Presupuesto Participativo con base regional o temática. 5.8. Tipología de Presupuesto Participativo según las formas de participación: investigaciones y encuestas, reuniones y asambleas presenciales o a través de canales virtuales. 5.9. Tipología de Presupuesto Participativo según las formas de regulación del proceso. 5.10. Tipología de Presupuesto Participativo según de donde provenga la iniciativa de presentación de propuestas.-CONCLUSIÓN.-BIBLIOGRAFÍA.
\end{abstract}

El aumento año tras año del número de experiencias con la denominación de Presupuesto Participativo en todo el mundo, con características y objetivos muy distintos debido a las diferencias políticas, económicas, culturales y sociales de los países, hacen necesaria una reflexión seria y profunda sobre los elementos que conforman el Presupuesto Participativo.

\footnotetext{
1 El Presupuesto Participativo es una de las líneas de investigación del GPCGP — Grupo de Investigación «Control Social del Gasto Público», del Departamento de Administración Pública de la Facultad de Ciencias y Letras de la UNESP - Universidade Estadual Paulista «Júlio de Mesquita Filho», situada en el Estado de São Paulo, Brasil, del que forman parte los autores del artículo Valdemir PIRES (www.pires.pro.br) y Carmen PINEDA NEBOT (carmenpinedanebot@hotmail.com).
}

Los autores quieren agradecer las valiosas sugerencias de Miguel BELTRÁN VILLALVA y Eduardo ZAPICO GoÑI que, sin duda, han enriquecido notablemente este trabajo. 
Qué experiencias pueden ser consideradas Presupuesto Participativo y cuáles no, es una de las preguntas clave que se comienzan a plantear los investigadores interesados en estos temas (GANUZA, 2007; NAVARRO, 2008; SINTOMER, HERZBERG y RÖCKE, 2006; GANUZA y GóMEZ, 2008). Aunque la mayoría de estos intentos de clasificación se apoyan fundamentalmente en los procedimientos que utilizan las distintas experiencias para desarrollarse (GANUZA, 2007) o en el rendimiento movilizador (NAVARRO, 2008) olvidando siempre un aspecto muy importante: el presupuestario.

En este artículo se intenta de una manera objetiva responder a algunos de estos interrogantes o por lo menos plantear algunas cuestiones que puedan servir para abrir el debate sobre el tema de la participación de los ciudadanos en el proceso presupuestario, todo ello desde una visión basada no sólo en el aspecto participativo sino también desde un aspecto más técnico, como es el económico. Éste último ausente a pesar de su importancia en muchos de los trabajos e investigaciones que se realizan sobre el tema.

\section{INTRODUCCIÓN}

El Presupuesto Participativo es una metodología de gestión presupuestaria pública que en los últimos 20 años, aproximadamente, consiguió la condición de práctica potencialmente innovadora y renovadora de la democracia y de la calidad del gasto público, que ha sido reconocida por las más diversas instituciones, incluso internacionales (ONU, FMI, Banco Mundial, diversas ONG's de amplia penetración en muchos países), y adoptada por gobiernos locales y nacionales en todos los continentes. Se trata de una de las más relevantes experiencias e innovaciones para el control social de la gestión presupuestaria, asociando democracia y hacienda pública de un modo bastante satisfactorio para ambas.

El Presupuesto Participativo (Participatory o Participative Budget, en inglés; Bilancio Partecipativo, en italiano; Budget Participatif, en francés; Beteiligungshaushalt, en alemán) es una expresión que es utilizada para denominar varios tipos de experiencias que comprenden, simultáneamente, algún grado de implicación de la población o de la sociedad civil en los diferentes procesos de decisión relacionados con las haciendas y las políticas públicas o con la gestión de proyectos de interés colectivo.

Desde mediados de los años 90 ha ido creciendo exponencialmente el uso de la expresión en todo el mundo, debido al interés que el asunto despierta entre gobernantes; líderes políticos, comunitarios y sindicales, periodistas, investigadores académicos y técnicos de instituciones multilaterales de desarrollo y financiación. Tal difusión del concepto se debe en gran medida a la intensa propaganda promovida por diversos sectores gubernamentales y mediáticos, a la abundancia de folletos y revistas referentes a las experiencias llevadas a 
cabo en muchos y distintos lugares, a la creciente publicación de textos analíticos (de naturaleza académica o no) y, también, a las facilidades de difusión proporcionada por la red mundial de internet. Una investigación usando el buscador «Google», en octubre de 2007, teniendo en cuenta solamente la expresión completa (o sea, colocando entre comillas para evitar que sean detectadas citaciones en las que apenas una de las palabras que la componen aparezcan) dio el siguiente resultado.

\begin{tabular}{|l|c|}
\hline \multicolumn{1}{|c|}{ Expresión } & Citas \\
\hline «Orçamento Participativo» & 898.000 \\
\hline «Presupuesto Participativo» & 584.000 \\
\hline «Participatory Budget» & 91.200 \\
\hline «Participative Budget» & 912 \\
\hline «Bilancio Partecipativo» & 105.000 \\
\hline «Budget Participatif» & 89.200 \\
\hline Beteiligungshaushalt & 27.000 \\
\hline Total en los seis idiomas & 1.795 .312 \\
\hline
\end{tabular}

Entre las citas encontramos desde noticias sobre reuniones de Presupuesto Participativo y reglamentos internos de experiencias en marcha o que han finalizado, hasta textos de tesis y artículos académicos, pasando por compilaciones de literatura sobre el asunto y juegos. Hay pocas citas de contenido negativo: en general, los materiales disponibles informan o, más comúnmente ofrecen ayudas para entender el asunto y proporcionan elementos de apoyo a los interesados en implementar experiencias. Crece el número de gobiernos, fundamentalmente locales y regionales, que incluyen el Presupuesto Participativo en sus portales, sitios o páginas web.

Paralelamente aumenta el número de estudios y publicaciones sobre el Presupuesto Participativo en distintos idiomas, así como la frecuencia con la que se realizan eventos internacionales específicos sobre el asunto.

Por superficial que sea, cuando se abordan textos académicos, de opinión o periodísticos, virtuales o impresos, uno se da cuenta que lo que se entiende por Presupuesto Participativo varía ampliamente. Tal variación se comprueba también en el uso que de la expresión hacen gobiernos y entidades que lo practican, apoyan o defienden, así como las personas que hablan en eventos en que el tema es abordado. Se hace, por tanto, necesaria una explicación que permita a los que debaten sobre el tema y a los agentes interesados en el Presupuesto Participativo mantener algún grado de coherencia, necesaria en la discusión y en la acción. Contribuir a tal esclarecimiento es el objetivo del presente artículo. 


\section{Elementos para una definición del Presupuesto Participativo a partir de su origen en Brasil - el Presupuesto Participativo como proceso}

Una definición lo más exacta que sea posible del Presupuesto Participativo debe considerar su origen histórico. Desde ese punto de vista, el concepto de Presupuesto Participativo se refiere a las experiencias de gestión presupuestaria llevadas a cabo a principios de los años 90 por algunos gobiernos locales brasileños, en las que grupos organizados de la población y ciudadanos individuales pasaron a compartir con los gobernantes las decisiones sobre algunos items presupuestarios. Aunque la ciudad de Porto Alegre, capital del Estado de Rio Grande do Sul, sea la gran referencia internacional del Presupuesto Participativo ${ }^{2}$, sobre todo debido a la amplia divulgación que tuvo (por iniciativa de los cuatro gobiernos sucesivos del Partido de los Trabajadores (PT) - 1989-2004- y de órganos de prensa de gran repercusión internacional, como Le Monde Diplomatique y El Clarín) y a consecuencia de haber sido considerada una de las 42 mejores prácticas de gestión urbana, en 1994, por Habitat II - II Conferencia de las Naciones Unidas para los Asentamientos Humanos (BONDUKI, 1996, págs. 51-65), otras ciudades brasileñas realizaron el Presupuesto Participativo con igual éxito. En la administración 1989-92, fueron 13 municipios; 36 en la siguiente (1993-1996), entre 103 y 140 en el período 1997-2000, según TORRES E GRAZIA (2003), y el doble o el triple a partir de entonces, a pesar de la ausencia de datos precisos.

Además, existieron experiencias precursoras, que aunque no han recibido el nombre de Presupuesto Participativo contienen toda o una buena parte de sus características fundamentales. Entre estas se acostumbra a citar las tentativas de democratización de la gestión presupuestaria y de las políticas públicas locales practicadas por las ciudades de Lajes SC (ALVES, 1980), Boa Esperança SC (Covre, 1984), Vila Velha ES (Bossois, 1987) e Piracicaba SP (PESSOA, 1988; HERRMANN NETO, 1984).

La diversidad de objetivos y de metodologías adoptados por todas estas experiencias brasileñas, en vez de ayudar a explicar en que consiste el Presupuesto Participativo plantean al contrario aún más dudas, en la medida en que se trata de casos cuya heterogeneidad es significativa, tanto respecto a las expresiones utilizadas (delegado y consejero, por ejemplo, son funciones que varían de un caso a otro) como a los procedimientos adoptados (en algunas ciudades hay reglamentos internos, en otras una ley regula las actividades; en otras, el Presupuesto Participativo está en la Ley Orgánica del Municipio).

Es posible identificar, sin embargo, por lo menos dos elementos comunes en las experiencias pioneras de Presupuesto Participativo en Brasil, sobre todo si

\footnotetext{
2 En Europa las primeras experiencias de Presupuesto Participativo que se pusieron en marcha copiaban literalmente lo realizado en Porto Alegre durante sus primeros años de existencia, lo que ha provocado algunos problemas de orden práctico y un cierto rechazo.
} 
tenemos en cuenta las administraciones municipales de los períodos de 1989 a 1992 y de 1993 a 1996. Primero, estos fueron los períodos de ascensión del Partido de los Trabajadores (PT) en la política brasileña. El PT gano espacio y se consolido como alternativa electoral a partir de sus experiencias de gobiernos municipales (36 de 1989 a 1992; 53 de 1993 a 1996, 115 de 1997 a 2000, 187 de 2001 a 2004 y 411 de 2005 a 2008, siendo 9 de ellos capitales), consagrando lo que se paso a denominar el «modo petista de gobernar» (BITTAR, 1992). Ese modo específico de gobernar, que provoco una creciente simpatía y hasta respeto por parte de la oposición, consistía claramente en dos elementos claves: participación popular y políticas públicas de naturaleza redistributiva (tributación progresiva y gasto público concentrado en poblaciones y regiones de baja renta). Por tanto, las experiencias pioneras de Presupuesto Participativo en Brasil son clara consecuencia de una propuesta partidaria, que al mismo tiempo la fortalece y se nutre de ella para obtener apoyo electoral.

En segundo lugar, el Presupuesto Participativo, además de tener la marca de iniciación petista, adquiere también un perfil redistributivo, muy adecuado a la realidad brasileña de finales de los años 80 y comienzos de los 90 , marcada por crisis económicas y cambios políticos de los cuales el PT y el Presupuesto Participativo se beneficiaron, al presentarse como alternativas de cambio.

Las condiciones del nacimiento y crecimiento del Presupuesto Participativo en Brasil bajo el PT, darán como resultado una definición de esa práctica hoy reivindicada por algunos segmentos políticos como condición de validez; y rechazada por otros, por la naturaleza restrictiva que impone al proceso de identificación de prácticas autodenominadas presupuesto participativo. Esa definición exige, para hacer valida una práctica de gestión de recursos públicos como Presupuesto Participativo que tenga un doble carácter: deliberativo y distributivo.

El esfuerzo llevado a cabo por RIBEIRO E GRAZIA (2003) para elaborar un mapa de las experiencias de Presupuesto Participativo en Brasil en el período de 1997 a 2000, continuación de una tentativa anterior, de poco éxito, sobre el período 1989-1992, hace que sea importante lo que manifiesta respecto a las dificultades existentes para llegar a una definición satisfactoria de Presupuesto Participativo, a pesar que se refiere sólo al universo de prácticas brasileñas. Si tenemos en cuenta que esa investigación fue financiada por la Fundación Ford y por UN-HABITAT-PGU, y llevada a cabo por el Fórum Nacional de Participación Popular con la ayuda de miembros de gobiernos del PT y de organizaciones no-gubernamentales cercanas al modo petista de gobernar, es normal que se encontraran con el dilema inevitable entre trabajar con una definición abierta, para abarcar el mayor número de experiencias y evitar partidismo; o utilizar una definición restrictiva, corriendo el riesgo de encontrar pocos casos compatibles con ella e incurrir en alguna clase de partidismo. La habilidosa solución encontrada fue admitir de antemano que los investigadores actuaron sin renunciar a una dimensión del «Presupuesto Participativo como proyecto», 
acumulada de experiencias anteriores (de elaboración de mapas, de caracterización y de debates), o sea, admitir que eran investigadores interesados, no neutros y que su preocupación no era sólo identificar y delimitar las características del conjunto de prácticas de Presupuesto Participativo, sino también contribuir a reforzar un tipo específico de Presupuesto Participativo, del cual muchas experiencias de hecho se distanciaron y se distancian en Brasil. En buena medida fueron unos de los responsables de la asimilación del Presupuesto Participativo por agentes de fuera del universo petista.

Pero en términos de resultados la investigación, no fue mucho más allá de recoger informaciones valiosas como registro, respecto a las prácticas reales de Presupuesto Participativo en Brasil, en el período de 1997 a $2001^{3}$. Las conclusiones seguras a las que se llego con la investigación son muy elementales: apuntan a diversidad de metodologías y terminologías utilizadas, a pesar de la influencia de la experiencia de Porto Alegre; indican que la continuidad de las prácticas está siempre en riesgo y que el papel de los gobiernos es normalmente muy importante en la conducción de las actividades concernientes al proceso participativo. Aunque en algunos temas que a primera vista representarían descubrimientos del trabajo de campo incluido en la investigación, como, por ejemplo, el de la ampliación de los partidos que adoptaron el Presupuesto Participativo, las conclusiones no fueron definitivas: a veces el partido del alcalde no era del PT, pero el vice-alcalde era del PT o participaba en la coalición de partidos que elige al jefe del Ejecutivo ${ }^{4}$. Hasta la pretensión inicial de la investigación, de ser la primera aproximación a las experiencias en conjunto acabo perjudicando, se llegó a un censo que no es tal porque no partía de una definición del objeto de la actividad censada.

Todos esos límites, admitidos además por los investigadores, no diminuyen el valor y la importancia de los esfuerzos y de las conclusiones parciales y reconocidamente precarias a las que se llego con la investigación sintetizada por RIBEIRO E GRAZIA (2003), pero les impidieron mayores avances en el esfuerzo de llegar a una definición satisfactoria de lo que es el Presupuesto Participativo, limitándose a un deber ser marcado por posiciones que no se puede exigir que sean admitidas por todas las personas o grupos interesados en democratizar la gestión de los recursos públicos y/o mejorar la ejecución de los gastos gubernamentales.

\footnotetext{
3 El celo de los investigadores frente a un posible partidismo, pero sin renunciar a una visión particular de lo que sería un «buen Presupuesto Participativo», hizo que durante todo el tiempo se movieran bajo intensas contradicciones. Optando por una postura científica, objetiva, se concentraban en el universo de las prácticas y se distanciaban del «núcleo del proyecto» del Presupuesto Participativo; insistiendo en una postura política (la utopía del Presupuesto Participativo redistributivo y democratizante), perdían objetividad y cientificidad, necesarias para la investigación. No fue sin motivo que escogieran incluir en la investigación experiencias no propiamente dichas de OP, más así «autodenominadas».

4 Los partidos en Brasil, con frecuencia no pasan de ser siglas, ahora convenientes, ahora no convenientes o inconvenientes para éste o aquel político, desde un punto de vista meramente electoral, principalmente cuando se trata de competición en el ámbito del poder local (municipios).
} 
PRESUPUESTO PARTICIPATIVO: UNA TIPOLOGÍA PARA SUPERAR LOS LÍMITES...

Lo más preocupante que debía eliminarse de las conclusiones de la investigación no se refiere a las dudas posibles sobre la metodología que utilizaron, sino a la constatación que hacen de que

Los resultados alcanzados demuestran que el Presupuesto Participativo [en Brasil] es, actualmente [2003] una meta incluida en las intenciones de numerosos actores sociales, habiendo adquirido la condición de una propuesta con creciente capacidad de alcanzar la adhesión de administraciones locales y de segmentos de la población. Todavía, la expansión constatada del número de experiencias está lejos, aún, de significar una verdadera tendencia de inversión en las relaciones sociedad-gobierno en la red municipal brasileña. Esto ocurre no sólo como consecuencia de su pequeña dimensión en relación al total de los municipios ${ }^{5}$, sino también a causa de los limites observados en los procesos que, en caso de ser implementados, pueden llegar a asegurar la declaración de sujetos colectivos, la ampliación de la participación política y el fortalecimiento de la ciudadanía. (RIBEIRO E GRAZIA, 2003, pág. 113)

En el país de origen y asentamiento inicial del Presupuesto Participativo éste tiene poca expresión numérica y limitaciones de procedimiento y resultados que merecen ser considerados. En lo que existe consenso es que el Presupuesto Participativo tiene potencial para afirmar «sujetos colectivos», fortalecer la ciudadanía y transformar más substantiva la democracia. Con ello se llega a partir de la experiencia acumulada en Brasil a una definición del Presupuesto Participativo: se trata de una metodología concentrada en la búsqueda de superación de los limites de la democracia representativa para crear gobiernos menos autoritarios y más capaces de contribuir a la reducción de las injusticias y las desigualdades sociales que predominan especialmente en los países pobres ${ }^{6}$. Así, se puede decir que los casos de Presupuesto Participativo en Brasil, en conjunto, tienen mucho más que ofrecer como «núcleo de proyecto», como utopía, que como metodología eficaz y acabada. Eso no es poco, aunque una vez más, no satisface la demanda de una definición manejable de Presupuesto Participativo susceptible de imitación en otras realidades.

Cuanto más ambiciosas son las metas anheladas para las prácticas de participación popular en el control social del gasto público, cuanto más se dirigen a otras cuestiones que no sean sólo una mejora de la eficacia, la eficiencia, la efectividad y sustentabilidad de los gastos gubernamentales (democratización, protagonismo ciudadano, por ejemplo), más restrictivas se hacen las definiciones de Presupuesto Participativo, y mayores las dificultades para admitir las prácticas reales bajo ese nombre, así como para crear e implementar, con suficiente legi-

\footnotetext{
5 Brasil tiene 5.565 municipios

6 Durante los primeros años de implantación de la metodología de presupuesto participativo en Europa las mayores críticas se referían a esta cuestión. Se consideraba una metodología adecuada para países pobres o en desarrollo pero no apta para países desarrollados, como es el caso de los europeos.
} 
timidad entre los defensores del Presupuesto Participativo, nuevas experiencias más modestas. Es esta situación la que justifica un esfuerzo analítico para llegar a una definición más conveniente de Presupuesto Participativo de la que predomina en las experiencias pioneras de Brasil, aunque con el cuidado de no tirar por tierra una serie de esperanzas valiosas y necesarias que, prácticas excesivamente poco ambiciosas, cuando no oportunistas, pueden claramente malgastar.

A este grupo pertenece la definición propuesta por AVRITZER (2003, págs. 14-15), para quien el Presupuesto Participativo

es una forma de reequilibrar la articulación entre la democracia representativa y la democracia participativa, basada en cuatro elementos: [i] (...) cesión de la soberanía por aquellos que la detentan como resultado de un proceso representativo local; [ii] reintroducción de elementos de participación local y de delegación; [iii] principio da autoregulación soberana y [iv] reversión de las prioridades de distribución de los recursos públicos a nivel local.

En circunstancias en las que alguno de estos cuatro elementos no pudierán cumplirse, pueden ser implementadas prácticas más modestas, hasta que se creen las condiciones que las hagan posibles. O sea, una definición de Presupuesto Participativo simultáneamente dotada de posibilidades substanciales de transformación social y política y de viabilidad operativa inmediata, debe aceptar el Presupuesto Participativo como proceso y no como momento o mecanismo. Un proceso admite un resultado orientado por una esperanza, contiene un «núcleo de proyecto», en cambio «un conjunto de prácticas» llenas de contradicciones va poco a poco dando pasos desde lo que es a lo que será, compatibilizando el deseo/esperanza con los hechos, por medio de un todavía no capaz de anular el jamás, tantas veces lanzado contra las utopías.

\section{Elementos para una definición que se produce por la evolución del Presupuesto Participativo en América Latina - el Presupuesto Participativo como proceso histórico}

La falta de una definición de Presupuesto Participativo comienza a preocupar cada vez más en la medida en que las prácticas así autodenominadas y, con frecuencia, anunciadas como inspiradas en la experiencia brasileña, son cada vez más numerosas y el interés internacional en torno a ellas se amplía. Se comienza de hecho a descubrir que el problema más que de definición es de concepción: es posible adoptar la metodología teniendo como escenario, o como intención anunciada, diferentes objetivos, modos de decidir, formas de participar etc. Así se manifiesta acerca del asunto GOLDFRANK (2007, pág. 92), al iniciar un análisis de la experiencia de Presupuesto Participativo en América Latina:

Una definición amplia del presupuesto participativo lo describe generalmente como un proceso por el cual los ciudadanos pueden intervenir en la toma de decisio- 
PRESUPUESTO PARTICIPATIVO: UNA TIPOLOGÍA PARA SUPERAR LOS LÍMITES...

nes de al menos una parte del presupuesto público ${ }^{7}$. Definiciones más estrictas provienen de experiencias particulares de presupuesto participativo, especialmente la de Porto Alegre. De acuerdo con esta definición, el presupuesto participativo es un proceso abierto a cualquier ciudadano que quiera participar, que combina democracia directa y representativa, que implica deliberación (no sólo consulta), redistribuye recursos a los pobres, y es autorregulada, siendo los participantes los que definen las reglas que regulan el proceso, incluso los criterios de distribución de los recursos (ver, por ejemplo, AVRITZER 2002, GENRO y SOUZA 1997, y SANTOS 1998).

Ni una definición amplia ni una estricta son las más adecuadas en la construcción de una historia del presupuesto participativo. Una definición amplia incluiría muchos casos, tales como reuniones con grupos de presión, sesiones corrientes de los ayuntamientos, y sobre todo audiencias públicas especiales o referendos de asuntos presupuestarios específicos; en cambio la definición más estricta incluiría muy pocos ejemplos. Una definición más amplia quizá sería la que considera que el presupuesto participativo es un proceso por el cual los ciudadanos, como individuos o por medio de asociaciones, pueden voluntaria y regularmente intervenir en la toma de decisiones de, por lo menos, una parte del presupuesto público por medio de una serie de reuniones fijadas anualmente con las autoridades locales (la traducción es de los autores).

Como se puede ver, después de descartar las definiciones excesivamente amplias o restrictivas, propone otra, que entiende más adecuada para describir la historia del Presupuesto Participativo, que contiene los siguientes elementos de las definiciones existentes: i) participación voluntaria de los ciudadanos, como individuos o por medio de asociaciones, ii) capacidad de decidir por lo menos sobre una parte del presupuesto público, ii) en reuniones regulares compartidas con el gobierno.

La definición de GOLDFRANK (2007) descarta los elementos redistributivos, la autoregulación por los participantes y no sigue el camino de las discusiones sobre si la democracia debe ser representativa o participativa. Con ello, de hecho, su definición abre las puertas para la inclusión de casos de Presupuesto Participativo muy diferentes de los que en un principio se realizaron en Brasil, principalmente bajo el liderazgo del Partido de los Trabajadores y que, no por eso dejan de merecer la clasificación de Presupuesto Participativo. Quien vivió la experiencia brasileña debe saber que si las experiencias de Presupuesto Participativo puestas en marcha con la recuperación de la democracia se hubiesen limitado a los elementos presentados por este autor no habrían pasado de los primeros meses, si es que alguna hubiera sido tomada en algún momento en serio. Este hecho revela la importancia que las diferentes realidades históricas, ampliamente reconocidas por GOLDFRANK en el texto antes citado, tienen para una adecuada conceptualización del Presupuesto Participativo.

7 Esta definición esta tomada de las Naciones Unidas - Habitat. 
Por otro lado, la definición de GoLDFRANK no considera la admisión de experiencias de Presupuesto Participativo que no se relacionen de hecho con la temática presupuestaria y que no disfruten de una cierta regularidad ${ }^{8}$. Esa postura es importante porque de lo contrario habría un enorme número de acciones y actividades de interacción entre el gobierno y los ciudadanos que podrían reivindicar la condición de Presupuesto Participativo, sin siquiera acercarse a lo que es o pretende ser. Esta definición sufre, además del defecto grave de todas las definiciones que pretenden ser a-históricas: tiene la pretensión de validez general. Para que se comprenda plenamente esta afirmación, así como la gravedad mencionada, es posible imaginarse lo que ocurriría hoy en Brasil (2008), si, después de haber probado el Presupuesto Participativo con la forma de Porto Alegre (restrictivo), los ciudadanos se encontraran de repente con prácticas de Presupuesto Participativo que se incluyeran en la definición de GOLDFRANK (y que, por tanto, para él son Presupuesto Participativo), que los gobernantes pósPT aún con los retrocesos que hicieran al reducir las pretensiones del proceso participativo en el presupuesto público, continuaran llamándolo con el mismo nombre que tenía cuando se propone mucho más. De hecho, para aquellos que protagonizan una práctica deliberativa del Presupuesto Participativo y que, posteriormente son obligados a convivir con una práctica apenas consultiva, que antes tenía preocupaciones redistributivas y ahora se concentran apenas en responsabilidad (por ejemplo), es un contrasentido admitir que se trata de la continuidad del Presupuesto Participativo.

En la sección anterior de este texto se argumento que una buena definición de Presupuesto Participativo debe partir de la consideración de que es un proceso. En esta, después de lo que acaba de ser expuesto, se defiende que el proceso en el que se constituye el Presupuesto Participativo es un proceso marcadamente histórico, o sea, tiene sus objetivos, naturaleza, límites y potencialidades determinados por las condiciones socioeconómicas y culturales de aquellos que lo protagonizan, defendiéndolo y atacándolo, adhiriéndose y negándose a ello.

Es esclarecedor notar que el esfuerzo de GOLDFRANK para descartar la definición restrictiva oriunda de Brasil es esencial para acoger en su texto las experiencias de otros países latino-americanos: Bolivia, Perú, Guatemala y Nicaragua. Esfuerzo que, a la luz de lo que acaba de ser defendido aquí, no sería necesario. El Presupuesto Participativo se define en cuanto se practica, teniendo en cuenta las condiciones históricas de los que lo hacen, que no tienen que pedir permiso a nadie ni para inventar su modo de participar en la gestión de los recursos públicos, ni para copiar - perfecta o imperfectamente- el modo de hacerlo de otros. Lo importante, a la hora de utilizar un caso anterior como referencia, es conocer

8 Esos dos elementos están incluidos también en los cinco criterios de la definición metodológica mínima elaborada por los investigadores del proyecto Participatory Budgets in a European Comparative Approach. Perspectives and Chances of the Cooperative State at the Municipal Level in Germany and Europe, utilizada para poder reconocer las experiencias a estudiar. 
PRESUPUESTO PARTICIPATIVO: UNA TIPOLOGÍA PARA SUPERAR LOS LÍMITES...

la razón que lo mueve y averiguar si es la que interesa: si lo fuera, basta con intentar repetir sus resultados exitosos; si no lo fuera, sería necesario hacer las adaptaciones necesarias para la intencionalidad que se tiene en mente.

\section{El Presupuesto Participativo en otros continentes: riesgos y oportunidades de definiciones amplias}

Los artículos de FÖLSCHER (2007) y de SHALL (2007), en el libro editado por SHAH (2007), que tratan de la expansión del Presupuesto Participativo por Europa, Asia, África y Oriente Medio revelan, primero, que el Presupuesto Participativo no es solamente una práctica restringida a determinadas regiones y países y, segundo, que la amplia dispersión provoca cambios muy importantes en su significado así como en sus objetivos, cuando se comparan con las experiencias originales.

Se observa en ellos una postura bastante flexible al clasificar ciertas tentativas de participación popular en el control del uso de recursos como presupuesto participativo, lo mismo ocurre con los estudios de caso presentados en el CD ROM anexo al libro editado por SHAH (2007), que contempla casos de Presupuesto Participativo en el nível subnacional de los siguientes países: Bangladesh (RAHMAN, KABIR y RAZZAQUE, 2007), India (PAUl, 2007), Filipinas (BRILlAntes Jr., 2007), Rusia (KRYlOVA, 2007), África del Sur (ShAll, 2007), Tailandia (SUWANMALA, 2007) y Ucrania (KRYLOVA, 2007). Las circunstancias socioeconómicas y políticas existentes en esos países, regiones o ciudades aparecen como elementos potenciadores o restrictivos de las prácticas de control popular en el destino y no efectivo uso de los recursos. Es representativa la postura asumida en el libro por FÖSCHER (2007, pág. 127):

El Presupuesto Participativo en un sentido amplio se refiere al compromiso de los ciudadanos con el presupuesto público, incluyendo mecanismos como el análisis por la sociedad civil de las políticas de gasto público como un incentivo para el debate publico. Un uso más restrictivo del término muestra ejemplos en los cuales los ciudadanos tienen una participación directa en las decisiones sobre el uso de los recursos públicos normalmente a nivel local.

Además de elegir representantes para los consejos locales, los ciudadanos de algunas áreas municipales o sub-municipales de Europa Central y del Este están participando en las decisiones sobre los recursos públicos (la traducción es de los autores).

Con relativa frecuencia la intervención de agentes externos en las poblaciones como agencias de financiación y organizaciones no-gubernamentales, son importantes para la adopción de las metodologías escogidas. Señala FöSCHER (2007, pág. 143) que:

Excepto en algunos casos, las agencias de desarrollo y las ONGs internacionales han sido pioneras en la introducción de experiencias de presupuesto participativo en 
Europa Central y del Este. Y en donde las iniciativas provienen de la acción local, las organizaciones internacionales financian a las organizaciones claves y los contactos con redes de organizaciones de la sociedad civil de todo el mundo preceden a las acciones locales (la traducción es de los autores).

La creación de ambientes de transparencia es señalada muchas veces como un avance muy importante en lugares donde hasta poco antes de plantearse poner en marcha el Presupuesto Participativo existían regimenes cerrados y donde el Estado y la administración pública presentan debilidades esenciales. En otras palabras, en un significativo número de experiencias los interesados en mejorar el uso de los recursos deben enfrentarse a un ambiente hostil y a la mejora de la gobernanza en los órganos públicos. A pesar de las limitaciones los resultados son encarados como avances, necesitando siempre mejoras de los más diversos tipos. Refiriéndose a las experiencias del África Sub-sahariana, SHALl (2007, pág. 213) concluye que:

La participación en el proceso presupuestario es aún una novedad en la mayoría de los países (...). Ya, sin embargo, han aumentado el número de proyectos que benefician directamente a las comunidades y que corresponden a las prioridades identificadas a través de los procesos de participación. La relación entre los ciudadanos y las autoridades locales han mejorado, y los ciudadanos tienen una actitud más positiva y una opinión mejor de las autoridades locales (la traducción es de los autores).

La utilización de definiciones amplias y flexibles para identificar y clasificar las experiencias de Presupuesto Participativo trae consigo un riesgo y una oportunidad. El riesgo es el de banalizar hasta tal punto la metodología, que pase a estar asociada a prácticas cuyos resultados perviertan la propuesta, colocándola en el saco común de las promesas no cumplidas en los esfuerzos por una democracia substantiva. En muchas situaciones este riesgo es asumido, sin medir las consecuencias, por agentes e instituciones que sólo quieren legitimar sus propuestas o su modo de proceder por medio del uso de una metodología de gestión y de participación política que últimamente va ganando visibilidad en todo el mundo. Así ocurre cuando una agencia de financiación con el objetivo exclusivo de presionar a los que reciben los fondos para que hagan mejor uso de los recursos impone controles que implican algunas formas, no siempre las mejores o las más prometedoras, de participación de la población beneficiaria. Lo mismo ocurre cuando ciertos grupos políticos echan mano de la intensificación del contacto con los ciudadanos-electores, por medio del Presupuesto Participativo, para simplemente fortalecer su musculatura política frente a fuerzas opuestas menos abiertas a la ampliación del control popular en el uso de recursos. No se debe descartar tampoco la posibilidad de grupos específicos de profesionales de consultoría especializada, intentando conseguir contratos convenientes para su propio interés.

A su vez, la oportunidad abierta por una definición menos limitada y restrictiva para la adopción de numerosas prácticas de Presupuesto Participativo, está 
relacionada con el aumento de las posibilidades de que algunas experiencias con poco contenido democratizante y/o que aumentan el buen desempeño gubernamental se transformen, paulatinamente en modelos con resultados crecientemente apreciables. Una definición cerrada y prohibitiva del Presupuesto Participativo puede restringir de inmediato el aprecio por la metodología, debido a las dificultades para implementarla al principio. El alcance que el Presupuesto Participativo pueda tener se reduce si se utiliza una definición más amplia. El cuidado que hay que tener es asegurarse la continuidad de la experiencia con sucesivas mejoras, con el objetivo de aumentar las exigencias atendidas por ella, caminando hacia una definición más restrictiva del Presupuesto Participativo. Esta perspectiva coincide plenamente con la conclusión de las dos secciones anteriores de este articulo, de que la definición de lo que sea el Presupuesto Participativo debe presentarse como una metodología que se configura a lo largo de un proceso histórico, marcada por aciertos y errores, limites y potencialidades, que deben ser comprendidos y aprovechados o minimizados todo lo que sea posible por los protagonistas. Los actores individuales aprenden, el desafío es conseguir que el aprendizaje sea colectivo y suficiente para soportar los desgastes de las dificultades cotidianas y de los retrocesos presentes en todo proceso de transformación de la realidad y de las relaciones. De ahí la importancia de la formación de los actores en los procesos de Presupuesto Participativo ${ }^{9}$.

\section{Definiciones a partir de las fracturas ideológicas (movimentalismo x gerencialismo) - el Presupuesto Participativo como innovación institucional}

Entre la definición aceptable (restrictiva) del Presupuesto Participativo presente en las experiencias pioneras de Brasil y de algunos países de América Latina, iniciadas generalmente por grupos y partidos de izquierda, y las definiciones posibles (pero abiertas) actualmente de moda, de casos nacionales y locales en los más diversos países y continentes, que utilizan diferentes metodologías y se orientan por los más distintos objetivos, la diferencia existente es muchas veces ideológica.

Los presupuestos participativos autoregulados, más deliberativos, de naturaleza redistributiva predominaron al principio (sin que hayan desaparecido, pero si disminuido con el tiempo), principalmente debido a la coyuntura política en la que fueron iniciados (democratización o redemocratización en América Latina y necesidad urgente de gobiernos más atentos a los graves problemas sociales como consecuencia de la crisis económica y del modelo de financiación de las políticas públicas) y al carácter progresista de las fuerzas políticoideológicas y de partidos en ascenso que hicieron del Presupuesto Participativo

9 Al respecto, ver PIRES y PINEDA (2008). 
su bandera de lucha. Los Presupuestos Participativos pioneros llevan la marca del llamado movimientalismo, o sea, de los movimientos sociales de los años 70-80 que fueron los responsables de las jornadas de lucha de las poblaciones de las periferias urbanas y del campo y que hicieron desaparecer las dictaduras militares de los países en los que aún existían, abriendo espacio para un modelo de acción política más abierto a la participación ciudadana.

Los presupuestos participativos más recientes - con excepciones, evidentemente - , responden mucho más a un matiz gerencialista, típico de la primera ola de reformas del Estado (FERLIE y otros, 1996; BRESSER-PEREIRA, WILHEIM y SOLA, 1999). El objetivo central que preside estas experiencias a través de todo el mundo es el de mayor responsabilización de los gobiernos en el uso de los recursos y de mayor responsabilidad en la relación con las comunidades al enfrentarse con los ingresos y los gastos. Aspectos técnicos, más que políticos, concurren en la defensa del Presupuesto Participativo gerencialista. Es lo que explica, según analistas más a la izquierda, que instituciones antes insensibles a los llamamientos de los movimientos sociales y a los gritos de protesta por la democracia substantiva (como el Banco Mundial y el Fondo Monetario Internacional, por ejemplo) hoy hagan coro en defensa de diversas formas de control del gasto público que se benefician de la participación popular.

Muchos argumentan hoy en Brasil, origen del Presupuesto Participativo, contra lo que denominan «convergencia maldita» en torno a él y a otras formas de participación popular (como los consejos gestores de políticas públicas previstos en la Constitución brasileña de 1988). De hecho, hace algunos años nadie podía imaginarse en Brasil, al Banco Mundial y al Fondo Monetario Internacional defendiendo las mismas banderas de los movimientos sociales de los años 70-80. Entonces esas agencias multilaterales eran la cara visible, y atacada en las calles y tribunas, de las ideas neoliberales (que predominaban en la década de los 90), que imponían a Brasil políticas económicas recesivas y eran, por tanto, las causantes del desempleo, del deterioro de las condiciones de vida en las ciudades y de las políticas sociales, condiciones contra las cuales se levantaron los diversos grupos de la sociedad civil. Aún suena en la memoria de muchos militantes políticos, algunos de ellos habiendo iniciado sus actividades en los años 80, el eslogan «Fuera el FMI» o «Abajo el imperialismo americano».

A final de los años 90, el Grupo de Estudios sobre la Construcción Democrática, de la Universidade Estadual de Campinas, publicó un interesante dossier (GECD-UNICAMP, 1998-1999a) en el que sus investigadores hicieron una lectura bastante atenta sobre la nueva realidad política posdemocrática de Brasil, en la cual el Presupuesto Participativo prolifero. Según estos investigadores, después de haber protagonizado una intensa y exitosa lucha contra la dictadura y de haberse constituido en sujetos políticos innovadores y prometedores, caminando en la dirección del robustecimiento de la sociedad civil, por medio de la creación de una esfera pública (GECD-UNICAMP, 1998/1999b), los nue- 
vos movimientos sociales (SADER, 1988; DAGNINO, 1997) estaban entrando en el nuevo milenio con otras características. El GECD-UNICAMP, a diferencia de otros analistas, que hablaban de la crisis de los movimientos sociales o de su reflujo (GOHN, 1993, por ejemplo), entendían que se trataba, en realidad, de una transformación. Los combativos grupos que desde finales de los años 70 hasta principios de los años 80 se manifestaban en defensa de la democracia, de políticas sociales redistributivas y de políticas urbanas progresistas, en los años 90 se enfrentaban con una nueva realidad: el Estado se democratizaba y dialogaba con los grupos organizados; nuevas tareas se planteaban en el día a día de todos los que estaban implicados en la acción política y en la implementación de políticas públicas. Una gradual transformación de los objetivos y de las formas de actuación fue sucediendo, como consecuencia de por lo menos seis cambios producidos por la nueva realidad de los años 90, identificados por el GECD/ UNICAMP-c (1998/1999-c, págs. 25-26):

1. en primer lugar, una mayor disponibilidad de la posibilidad recién instaurada de que los actores de la sociedad civil negocien con el Estado, como demuestran las experiencias de asociación existentes actualmente entre el Estado y los actores de la sociedad civil; 2. una tendencia a la institucionalización de los movimientos y de las ONG's, en el sentido de una mayor "profesionalización», eficacia en los resultados, captación y optimización de recursos materiales y humanos; 3. ampliación de los temas abordados por la sociedad civil y del número de actores, que se ven legitimados en este nuevo escenario de libertad de asociación; 4.manifestación más explícita de la pluralidad de intenciones, de la heterogeneidad de posiciones y demandas - fracturas, conflictos, ambigüedades - ya existentes en el interior de la sociedad civil y que aparecen con más fuerza en un escenario en el que los proyectos no se unifican más en torno de un objetivo común, como es la lucha contra la dictadura; 5. mayores posibilidades, teniendo en cuenta el nuevo escenario de «libertades democráticas», de actuación en la esfera pública, y por tanto de ampliación del grado de publicidad de las demandas y problemas sociales planteados por la sociedad civil; 6. articulación de los movimientos sociales entre si y con diferentes actores sociales en redes, más o menos formalizadas, configurando un nuevo patrón de actuación.

«Es en este nuevo contexto en el que el propio termino sociedad civil pasa a ser objeto de varios significados diferentes y a ser discutido. Son significados atribuidos a proyectos políticos diversos y a veces antagónicos.» (GECD/UNICAMP, 1998/1999-c, pág. 27).

De hecho, la redemocratización no fue en los años 90 en Brasil el único dato nuevo, de impacto profundo sobre la sociedad civil y sus relaciones con el Estado: la propia visión sobre el papel del gobierno, fruto de una intensa ola liberalizadora en todo Occidente, cambio rápida y significativamente, sin mucho margen de maniobra para que las fuerzas políticas (en el interior de la sociedad civil o ocupando el aparato del Estado) pudiesen oponerse con éxito. Irónicamente, el Estado «cayó en manos» de la sociedad civil cuando su soberanía se redujo; «unida» a los movimientos populares cuando su capacidad de financia- 
ción ya no bastaba para garantizar las políticas sociales. ¿Victoria de Pirro de los prometedores movimientos sociales de los años 70/80?

Para el futuro del Presupuesto Participativo como metodología prometedora para la democracia y la instauración de gobiernos más volcados en cuestiones sociales no se trata, de aquí en adelante, de maldecir la convergencia ideológica en torno de la bandera que representa. No es con la exclusión de tentativas menos progresistas de Presupuesto Participativo, expulsadas del reino de la utopía, ni por medio de la etiquetación negativa por el uso de definiciones restrictivas de lo que es el Presupuesto Participativo, por la que se llegara a una correlación de fuerzas más favorables a los elementos democratizantes, de más autonomía y redistributivos.

Además, hay que reconocer que las experiencias de Presupuesto Participativo lideradas por fuerzas políticas más a la izquierda tienden a recalcar el adjetivo «participativo» de la metodología, politizando hasta tal punto las prácticas que los aspectos técnicos que ella incluye («presupuesto», como instrumento legal y de gestión) terminan abandonados, perjudicando los resultados posibles. Y, por otro lado, yendo en la dirección del extremo opuesto del espectro ideológico, las experiencias casi se limitan al sustantivo «presupuesto» que da nombre a la metodología, tendiendo a una despolitización que pone en duda la validez de la participación. O sea, más que negativa, la convergencia ideológica es necesaria para mejorar el Presupuesto Participativo. En cuanto a los resultados, más o menos progresistas, corresponde a las fuerzas existentes que se correlacionen para producir los que más les convienen, actuando en un ambiente democrático y fortaleciendo la esfera pública.

Se llega, pues, a un tercero y relevante elemento para una definición del Presupuesto Participativo: es un proceso (según el capitulo 1) histórico (según el capitulo 2) de innovación institucional. De hecho la institución presupuestaria, al reflejar las diferentes concepciones del Estado y de las relaciones Estadosociedad predominantes en cada tiempo y lugar siempre fue objeto de reformas desde su creación a comienzos del siglo XIII. Lo mismo ocurre con la democracia, que sufre siempre avances y retrocesos según las diferentes correlaciones de fuerza.

\section{Definiciones adjetivadas - una tipología del Presupuesto Participativo a partir de los objetivos y diseños de las experiencias}

Si el Presupuesto Participativo debe ser encarado desde el punto de vista de un proceso histórico de innovación institucional, no es adecuado tener una definición, sea amplia o limitada, pero si una tipología o varias tipologías, en la cual o en las cuales los diferentes objetivos y formatos de las practicas puedan ser encuadrados. En esa tipología o tipologías no sólo deben caber casos que se 
sitúan en diferentes puntos del amplio espectro ideológico, sino también los diferentes grados de distancia que las prácticas puedan tener en términos de impacto sobre la democracia y sobre la gestión pública. Con ello se evita lo que de otra manera no sería posible: la eliminación de casos concretos menos pretenciosos o la inclusión forzada de casos que no merecen figurar en la lista de experiencias de Presupuesto Participativo (como, por ejemplo, las tentativas oportunistas que llevan el nombre de Presupuesto Participativo pero no se comprometen ni siquiera minimamente con sus fundamentos). Claro está que tal tipología o tipologías, para permitir los descartes necesarios deben partir de un núcleo mínimo de exigencia.

\subsection{Tipología de Presupuesto Participativo según el objetivo: transparencia, fiscalización, consulta y deliberación}

Un punto de partida bastante operativo para iniciar una tipología es la que distingue los cuatro objetivos básicos que pueden establecerse para mejorar la gestión presupuestaria relacionados con una mejor gestión y un mayor control por la sociedad: transparencia, fiscalización, consulta y deliberación, pudiendo esta última ser tanto más efectiva cuanto más se avance en el interior del ciclo presupuestario, constituido por las siguientes fases: elaboración, aprobación, ejecución, control y evaluación.

La transparencia presupuestaria consiste en la creación de las condiciones suficientes para que las decisiones, las acciones y los resultados del cobro de impuestos y del gasto de los recursos públicos sean visibles y comprensibles para cualquier individuo interesado o, por lo menos, para aquellos que tienen en sus manos la tarea formal o funcional para en nombre de la sociedad, resguardar la calidad de las haciendas públicas con base en criterios pre-establecidos. Ello requiere mucho esfuerzo y recursos, pues para hacerlo posible es necesario que todo el ciclo presupuestario se apoye en una estructura y en una metodología que sean capaces de registrar adecuadamente las decisiones, las operaciones y los resultados de los ingresos y de los gastos. Tal estructura y metodología se concretan por medio de un conjunto de aparatos y habilidades que hoy en día están disponibles fácilmente, aunque cuestan mucho: conocimientos de hacienda pública, de administración financiera, de contabilidad, regulación, bancos de datos y capacidad de procesarlos, medios de los más diversos tipos y costes.

La transparencia presupuestaria nace prácticamente con la idea del presupuesto público, y va evolucionando bajo el impulso de dos variables: tecnológica y política. La variable tecnológica permite los avances (con las antiguas fichas de cartón y los informes en papel de la contabilidad tradicional se podían hacer menos cosas que con los bancos de datos informatizados y los informes magnéticos de hoy en día); la variable política define si lo que es posible, en términos de transparencia, será o no llevado a cabo. De ese modo, las prácticas concretas que se crean para la búsqueda de una mayor transparencia presupues- 
taria pueden perfectamente ser clasificadas como Presupuesto Participativo, entre otras cosas porque sin esa transparencia el Presupuesto Participativo no es posible. Aunque sólo deseen ésto, los grupos implicados con el Presupuesto Participativo de esa categoría deben obtenerla al principio.

Tres elementos básicos dificultan el avance de la transparencia presupuestaria: la no disponibilidad de recursos tecnológicos, la falta de preparación profesional y la poca voluntad política. Las dos primeras carencias pueden ser resueltas, respectivamente, con recursos financieros y formación. La última debe conseguirse por los actores y agentes contrarios a la falta de transparencia presupuestaria, por medio de su actuación y presión. El Presupuesto Participativo es un canal y una herramienta que se presta a esta actuación y que puede ejercer esa presión. En sociedades recién democratizadas, en fase de democratización o en lucha por la democracia, el objetivo de la transparencia presupuestaria tiende a ser suficientemente movilizador para fortalecer las propuestas de Presupuesto Participativo ${ }^{10}$.

La fiscalización presupuestaria también da sustancia suficiente a las prácticas de grupos que reivindican estar practicando el Presupuesto Participativo. Ella, aunque en menor grado que la transparencia, acompaña al presupuesto público desde su nacimiento. En el contexto de la democracia representativa, la fiscalización es una práctica de control de un poder sobre el otro. Normalmente el poder Legislativo fiscaliza al poder Ejecutivo en lo que respecta a la planificación y ejecución presupuestaria, con o sin la ayuda de equipos técnicos, como, por ejemplo, los Tribunales de Cuentas. Mientras tanto, ese mecanismo, absolutamente necesario puede no ser suficiente, ya porque haya mucho por controlar y recursos escasos para crear el control. Por ello, el Presupuesto Participativo propone una mayor cualificación de la vigilancia, al intentar defender los puntos de vista de un conjunto más amplio de actores que el de los que ostentan cargos ejecutivos, legislativos y de control externo formal. De la misma manera que reivindica una transparencia que va más allá de los que poseen el poder formal (con explicaciones más detalladas y comprensibles para el ciudadano común), el Presupuesto Participativo pide mayor fiscalización de la que esta formalmente establecida, lo que implica momentos y espacios de prestación de cuentas y el suministro de informaciones más allá de las exigidos por la democracia representativa tradicional. La fiscalización vía Presupuesto Participativo requiere un «cuerpo-a-cuerpo» mayor entre los que tienen el poder formal y los ciudadanos comunes, en una convivencia cotidiana que tiene un gran potencial para impedir abusos y desvíos por el simple hecho de que se sabe que un mayor número de «ojos y oídos» están atentos (efecto preventivo del control).

El Presupuesto Participativo puede ser también consultivo. En este caso el gobierno opta por tomar decisiones después de obtener opiniones, plantear de-

10 Los casos de Presupuesto Participativo del Este de Europa, descritos por FöSCHER (2007) son ilustrativos al respecto. 
bates, someter propuestas a la crítica y revisar sus propuestas teniendo en cuenta las críticas recibidas. Pueden ser diversos los modos para proceder a las consultas, desde encuestas de opinión hasta intensos procesos de interlocución de los gobernantes con segmentos representativos de la sociedad civil. La voluntad política de oír y respetar los resultados de las consultas puede variar de un caso a otro y de un período a otro. El proceso consultivo puede, con el tiempo o como resultado de alteraciones en la correlación de fuerzas evolucionar hacia un proceso deliberativo.

La deliberación, posibilidad de los ciudadanos comunes de decidir junto con el gobierno sobre el destino de los recursos públicos, aparece como un elemento definidor ampliamente aceptado por las prácticas de Presupuesto Participativo en todo el mundo. De tal forma que algunos no consideran Presupuesto Participativo las prácticas que se limitan a la transparencia y/o a la fiscalización. O sea, cuando el elemento de deliberación compartida está presente no se cuestiona la validez de la práctica como Presupuesto Participativo. Es preciso, sin embargo, admitir que si tal deliberación ocurre sin transparencia, los ciudadanos comunes pueden ser fácilmente embaucados. Por otro lado, si no existe fiscalización, la probabilidad de producirse lo que ha sido decidido diminuye, en muchos casos drásticamente ( si el gobierno estuviera haciendo el Presupuesto Participativo por simple oportunismo electoral, por ejemplo). Lo que se está afirmando es que es engañosa la tendencia que supone que incluir la deliberación en la definición de lo que sea Presupuesto Participativo basta para darle calidad. Es posible, en cambio, que una práctica que se inicie reivindicando simplemente transparencia evolucione hacia la deliberación, con el tiempo. Por otro lado, es probable que ocurra que la falta de transparencia destruya un proyecto que se ha creado con el propósito de tomar decisiones basadas en el entendimiento entre el gobierno y los grupos de la sociedad civil.

Después de todo, la deliberación puede darse de diversas maneras y en diferentes fases del ciclo presupuestario. El más común es aquel en que el gobierno discute con la población en la fase de elaboración de la propuesta presupuestaria ${ }^{11}$. Pero si ésta, después de aprobada, no puede materializarse íntegramente, será necesario tomar decisiones durante la fase de ejecución. Si disminuyen los ingresos a lo largo del año, por ejemplo, ¿cuál o cuales de las decisiones de gasto será o serán modificadas? ¿De qué modo lo que se decidió originalmente es alterado, con o sin participación popular?

Así mismo, considerando que la deliberación se dé solamente en la fase de elaboración, todavía hay que decidir si será sobre todo el presupuesto (lo que es prácticamente imposible), sobre las inversiones o parte de ellas (lo más usual) ${ }^{12}$,

\footnotetext{
11 Es el caso de la mayoría de las experiencias europeas.

12 En muchas experiencias españolas comienzan con una parte del gasto en inversiones que va creciendo conforme lo hace la experiencia, incorporando con el tiempo a otras áreas o a otros programas de gasto.
} 
sobre cierto tipo de gasto corriente (más gasto en salud preventiva o en atención en urgencias, por ejemplo) etc. Eso quiere decir que el diseño final de experiencias concretas da margen a múltiples posibilidades, de acuerdo a cada realidad y grupo de actores.

En síntesis, hay cuatro tipos de Presupuesto Participativo posibles a partir de lo que se ha discutido hasta ahora: Presupuesto Participativo para mayor transparencia $^{13}$, Presupuesto Participativo con carácter fiscalizador, Presupuesto Participativo consultivo y Presupuesto Participativo deliberativo (el deliberativo también se desdobla en diversos subtipos según la amplitud de lo que se delibera y en la fase en la que se produce el proceso deliberativo). Varias combinaciones son posibles: Presupuesto Participativo deliberativo y fiscalizador, por ejemplo; o Presupuesto Participativo deliberativo en las inversiones y fiscalizador sobre el gasto corriente.

En los municipios en los que todo está por hacer, se puede optar por un proceso histórico e innovador de Presupuesto Participativo que comience con la lucha por la transparencia, pero con la vista puesta desde el principio en la fiscalización y en la deliberación. Esa perspectiva combinada con la estrategia, que deben tener claro los protagonistas, puede aumentar las posibilidades de sustentabilidad del Presupuesto Participativo. Caminando paso a paso de acuerdo a la correlación de fuerzas que se puedan establecer en cada momento. Al contrario, la falta de claridad sobre la necesidad de adecuación entre la realidad vivida y la propuesta de innovación puede ser causa del fracaso de las tentativas de implantación del Presupuesto Participativo ${ }^{14}$. La apertura de esas dos posibilidades sirve para reforzar la inadecuación de las definiciones simplistas, demasiado amplias o demasiado restrictivas, para enfrentarse con la realidad del Presupuesto Participativo a partir de su dispersión por todo el mundo.

\subsection{Tipología de Presupuesto Participativo según las fases del proceso presupuestario: elaboración, aprobación, ejecución y evaluación}

Otro criterio en una tipología de los Presupuestos Participativos es el que distingue entre las fases del ciclo presupuestario en el que la participación ciudadana (por transparencia, fiscalización, consulta o deliberación) es admitida.

El ciclo presupuestario contiene las fases de elaboración, aprobación, ejecución y evaluación. La fase de elaboración es aquella en la que es concebida y

\footnotetext{
13 Éste es el caso de las experiencias alemanas de presupuesto participativo, que han concentrado más esfuerzos en mejorar la transparencia e información de la gestión local que en implicar a la ciudadanía en la toma de decisiones concretas sobre inversiones.

14 En muchos casos se echa en falta un diagnóstico serio de la realidad en el que se incorpore el mayor número de actores y un periodo de reflexión tanto al inicio de la experiencia como durante ella.
} 
estructurada la propuesta presupuestaria, contemplando la definición de prioridades, programas, proyectos y su adecuación a la estimación de ingresos para el período considerado. Una forma ratificada de llegar a la propuesta presupuestaria es aquella en la que el Poder Ejecutivo, por medio de un órgano central de planificación y presupuesto, pone en marcha a todos los sectores de actuación gubernamental para que cada uno contribuya en la formulación de prioridades y para la conciliación colectiva entre esas prioridades y los recursos disponibles. Un amplio proceso de discusión interna, movilizando técnicos y políticos encargados de las diferentes áreas de intervención pública, respetando criterios de eficiencia y de preferencia de prioridades se desarrolla a lo largo de un período de meses, hasta llegar a lo que el jefe del Poder Ejecutivo y su equipo político consideran la propuesta presupuestaria que se adecua a su plan de gobierno para el año. La forma más difundida de Presupuesto Participativo es la que incorpora al ciudadano al proceso deliberativo en esa fase ${ }^{15}$. Representa una postura de división del poder entre representantes y representados en la definición de prioridades presupuestarias, sin cuestionarse los mecanismos de la democracia representativa, sino ampliando el nivel de protagonismo de los electores.

Una vez definida la propuesta presupuestaria por el Poder Ejecutivo, tendrá que ser aprobada por el Poder Legislativo. En esta fase del ciclo presupuestario los parlamentarios, del gobierno o de la oposición, representando a los diferentes segmentos del electorado discutirán la propuesta del Poder Ejecutivo, alterándola con sus enmiendas y remitiéndola para su aprobación. En esta fase no hay mucho margen para la participación ciudadana, una vez que las prioridades que interesan a los ciudadanos ya fueron definidas, quedando únicamente una discusión más político-partidista acerca de la futura ley presupuestaria. La participación ciudadana que suele producirse en esta fase es la de la presión para que los parlamentarios no alteren las cantidades que fueron previamente acordadas entre el Poder Ejecutivo y los ciudadanos participantes en las reuniones de negociación de las prioridades contenidas en su propuesta.

Hay, también, situaciones en las que en ausencia de espacios y momentos para la discusión del presupuesto con la población promovidos por el Ejecutivo, el Legislativo organiza canales para ello, proponiéndose el hacer valer el principio de la cogestión en el momento de la discusión y deliberación parlamentaria de la propuesta del Ejecutivo. En 1999, en el Estado de Rio Grande do Sul (cuya capital es Porto Alegre, considerada como lugar de nacimiento del Presupuesto Participativo), el gobierno del Partido de los Trabajadores (PT) comenzó a implementar bajo cerradas disputas políticas y judiciales el Presupuesto Participativo del estado, llevando a un nivel superior de gobierno la propuesta de Presupuesto Participativo municipal realizada con éxito en Porto

15 Para ello es importante que se acomoden los tiempos de deliberación de los ciudadanos con los de los técnicos, pues en caso contrario perdería mucha efectividad y credibilidad el proceso. Lo que ha ocurrido con algunas experiencias españolas. 
Alegre. La Asamblea Legislativa, sin capacidad de afrontar la propuesta petista, terminó creando un espacio de discusión ciudadana liderado por los parlamentarios. Se creo un Presupuesto Participativo mixto, en el que los debates se dieran tanto en la fase de elaboración como en la de deliberación, incluyendo una relación directa de la población con ambos poderes, Ejecutivo y Legislativo (FARIAS, 2003).

La fase de ejecución presupuestaria, aquella en la que las decisiones se materializan o no, por medio de adquisiciones y contrataciones realizadas por el gobierno con los recursos públicos, es absolutamente crítica para el éxito del Presupuesto Participativo, ya que es en la que el grado de efectivo respeto de la voluntad popular puede ser evaluado. Buena parte de las experiencias de Presupuesto Participativo combinan amplia participación ciudadana en la fase de elaboración con participación ciudadana a través de representantes elegidos (delegados) en la fase de ejecución, correspondiendo a los representantes la fiscalización del cumplimiento de las deliberaciones y, hasta a veces, acompañando las obras para asegurar su calidad y unos costes adecuados, además de la honradez en los procesos de licitación y en el cumplimiento de los contratos. No siempre, por lo tanto, la intensidad y la calidad de la participación en la fase de elaboración se mantienen en la de fiscalización.

La fase de evaluación no se tiene en cuenta en la gran mayoría de las experiencias de Presupuesto Participativo. En buena medida ese relativo desprecio por la participación ciudadana en la fase de evaluación del proceso presupuestario reproduce lo que ocurre cuando el presupuesto público es administrado sin participación ciudadana: la evaluación generalmente se limita a un rito de poca sustancia para la calidad económico-financiera y democrática de los recursos públicos. Las tendencias contemporáneas de someter las políticas públicas a evaluaciones más rigurosas, basadas en teorías y métodos que están consolidándose puede cambiar este campo. La participación ciudadana puede ser además un ingrediente que acelere ese avance y se puede conseguir por medio de la inclusión de la evaluación en los Presupuestos Participativos.

El Presupuesto Participativo deliberativo ideal sería aquel que abarcase todas las fases del proceso presupuestario. Pero las condiciones concretas sobre las cuales se realiza impiden que todas las fases sean priorizadas, debido a la novedad de las prácticas, la complejidad de los temas abarcados y las diferentes correlaciones de fuerzas existentes. Hay, por tanto, una combinación mínima necesaria para la validez del Presupuesto Participativo deliberativo: participación amplia en la fase de elaboración y participación por medio de delegados en la fase de ejecución.

En cuanto a los Presupuestos Participativos por transparencia y fiscalizadores, pueden más fácilmente abarcar todas las fases del ciclo presupuestario, aunque tienen más valor cuando se aplican en la ejecución y la evaluación. 
En este segundo momento de esfuerzo para poder llegar a una tipología de Presupuestos Participativos, se concluye con la existencia de Presupuestos Participativos i) para la definición de prioridades (fase de elaboración del ciclo presupuestario), ii) para deliberación legal (fase de discusión y de deliberación legislativa), iii) para control de la ejecución (fase de ejecución de los ingresos y gastos públicos) y iv) para evaluación de procedimientos y resultados (fase de análisis de los resultados de un período de ejecución presupuestaria). Son posibles también casos mixtos.

Cuando se considera la plurianualidad del presupuesto público es posible incluir en las reuniones del Presupuesto Participativo la participación en la definición de los planes plurianuales, o documentos similares, que sirven para establecer metas a medio y largo plazo para los gastos públicos y/o para los resultados presupuestarios. En Brasil, donde las leyes presupuestarias anuales (LOA) deben ser la realización anual de parte de un Plan Plurianual (PPA - 4 años), o sea, hay vinculación de la LOA con el PPA, la participación ciudadana en éste es lógicamente necesaria. Pero la plurianualidad no está plenamente desarrollada hasta al punto de haber inconsistencias al producirse participación en la LOA y no haberla en el PPA. La importancia de la plurianualidad presupuestaria todavía no es apreciada por la población, estando aún en proceso de asimilación por los gobiernos. Tal vez la participación ciudadana en la LOA pueda incluir elementos de presión para que se de mayor importancia al PPA, reforzando iniciativas que están actualmente lideradas por algunos Tribunales de Cuentas de Brasil.

\subsection{Tipología de Presupuesto Participativo según el objeto de deliberación/consulta o fiscalización: gasto total, gasto en inversión, directrices de políticas públicas, ingresos y tributación}

También a partir del objeto de deliberación, consulta o fiscalización según cada caso se puede establecer una tipología de los Presupuestos Participativos. Son posibles Presupuestos Participativos que aborden solamente las inversiones (o parte de ellas), todos los gastos, ingresos/tributación y gastos o directrices de políticas públicas.

El tipo básico es el que trata de una parte de las inversiones ${ }^{16}$. El gobierno realiza la estimación de ingresos, de ella resta el gasto corriente y las inversiones que decide, y el valor restante será objeto de discusión en las reuniones participativas. Cuando la capacidad de inversión es alta, el poder deliberativo de la población es elevado. Si, por otra parte, la capacidad de inversión fuera

\footnotetext{
16 En España algo más de la mitad de las experiencias de presupuestos participativos (54,5\%) abren la participación de la ciudadanía únicamente en la decisión de pequeñas infraestructuras, mientras que el resto permite la participación en programas y servicios municipales. Eso significa que la ciudadanía puede también debatir qué cursos, programas culturales, proyectos, etc., realizará el Ayuntamiento.
} 
muy baja, el riesgo de frustración es tan grande que conviene evaluar si el Presupuesto Participativo debe ser puesto en marcha.

Un modelo más avanzado es el que abarca todas las inversiones. Éste es más atrayente para el ciudadano, por ofrecer mayores oportunidades para tener en cuenta sus necesidades inmediatas, pero conlleva un elevado riesgo de excluir inversiones esenciales que, por su baja visibilidad o interés inmediato difuso, pueden ser relegadas, un ejemplo podría ser la ampliación o mejora de la captación de agua o del tratamiento de aguas residuales. La buena práctica de la co-gestión exige que el gobierno sea sensible a las demandas y reivindicaciones de la población que siente los problemas cotidianos (planificación a corto plazo), pero exige también que los ciudadanos que reivindican comparen sus demandas con necesidades de inversión de efecto difuso y dilatado en el tiempo (planificación a largo plazo).

La discusión de todos los gastos implica que los gastos corrientes (gastos de personal, por ejemplo) estén puestos en cuestión. La lógica predominante entre los que reivindican la atención inmediata de sus necesidades va en la dirección de reducir costes para ampliar las inversiones, lo que no siempre es posible o deseable. La imposibilidad de reducción de costes se produce, por ejemplo, cuando es necesario realizar un reajuste salarial justo o cuando nuevas contrataciones son urgentes para la continuidad de la prestación de servicios. Lo no deseable es entendido en una situación en que una inversión anterior (un hospital, por ejemplo) exige nuevos gastos corrientes (contratación de médicos, por ejemplo) para surtir sus efectos. Lo que es posible, cuando se desea incluir los gastos corrientes en las discusiones del Presupuesto Participativo, es permitir el control de la productividad de los gastos, teniendo como objetivo eliminar ineficiencias y, con eso, reducir los costes, transfiriendo posteriormente lo ahorrado a inversiones. Se puede, por ejemplo, optar por una gestión de la flota de vehículos que exija menos recursos para combustibles y mantenimiento, invirtiendo el ahorro en la adquisición de máquinas y equipamientos.

Discutir el presupuesto como un todo - ingresos y gastos - es un procedimiento extremadamente complejo. Aunque la inclusión de los ingresos es bastante deseable ${ }^{17}$, una vez que la percepción de la limitación de recursos pasa a ser un dato a considerar al definir prioridades. Los propios límites de los ingresos pueden pasar a ser cuestionados: los ciudadanos pueden descubrir, por ejemplo, que el motivo para la limitación de ciertas inversiones provienen de una omisión del poder local al no ser capaces de sacar el máximo de ingresos de un determinado tributo. El impuesto sobre la propiedad inmueble, por ejemplo, puede estar siendo mal aprovechado por razones políticas; para evitar la oposición de los propietarios.

17 En España sólo en Albacete y Santa Cristina d'Aro se discuten una parte de los ingresos, los propios del ayuntamiento. 
La discusión de las directrices de políticas públicas puede ser muy interesante. Si los gastos en salud deben priorizar la acción preventiva o bien la curativa es una cuestión de gran repercusión para los gastos del área. Según la proporción de los gastos que cada uno de esos tipos de acción en el área de salud representan en el total de sus gastos, se llega a resultados mejores, con costes menores; la relación coste-beneficio se altera. Éste es, pues, un asunto presupuestario aunque enfocado desde el ángulo de las políticas públicas. El riesgo de ese recorte en la discusión es no llegar a valores financieros, es caer en las listas de intenciones sin mayores compromisos con la materialización.

Un sistema gradual parece ser, una vez más, la mejor táctica para llegar a un Presupuesto Participativo, cuando es percibido bajo el prisma del objeto que se considerara como objetivo. El Presupuesto Participativo se puede iniciar discutiendo una parte pequeña de las inversiones y seguir ampliando esa parcela; posteriormente puede incluir la evaluación de algunos gastos corrientes (combustibles, energía eléctrica y otros grandes grupos de gastos); paralelamente se pueden considerar las directrices de políticas públicas; varias combinaciones son posibles.

\subsection{Tipología de Presupuesto Participativo según el nivel de gobierno: local, regional o de estado, nacional}

Aunque es considerada sobre todo una metodología de gestión presupuestaria local, el Presupuesto Participativo puede ser utilizado por gobiernos nacionales e intermedios (de estado, provinciales, autonómicos o regionales). No es posible, sin embargo, la simple transposición del diseño adoptado en el nivel municipal a otros niveles. Estudiando el caso del Presupuesto Participativo del Estado do Rio Grande do Sul, FARIAS (2003) llego a interesantes conclusiones. Señalo que las fuerzas políticas implicadas son otras, que los problemas que hay que enfrentar no son los mismos, que la legislación del estado sobre el presupuesto es más compleja etc. Por tanto, la negociación en torno al diseño y los objetivos del Presupuesto Participativo en un nivel de gobierno superior es más delicada y exigente.

En el nivel local las demandas son de políticas públicas y servicios públicos destinados a un fin específico, lo que facilita la determinación de prioridades. En un nivel superior lo que se tratan son aspectos distributivos y estabilizadores (en el sentido de MusgraVE y MusgraVe, 1976), lo que complica la intervención de los ciudadanos, por razones técnicas intrínsecas. Una de ellas puede ser el modo de tratar con los ciudadanos la política monetaria y su relación con la política fiscal en el ámbito general de la política económica nacional.

Por otro lado, cuanto menor es la autonomía administrativa, tributaria y financiera de los gobiernos locales, menor es la importancia económica de los Presupuestos Participativos de ese nivel de gobierno. Por tanto, desde ese pun- 
to de vista, para tener algún sentido, los Presupuestos Participativos locales necesitan incluir la discusión sobre transferencias intergubernamentales y sobre las posibilidades de aumentar su autonomía. Eso quiere decir que los Presupuestos Participativos locales deben incorporar una orientación descentralizadora, aunque sin perder de vista que ciertas cuestiones de política económica difícilmente podrán ser tratadas si no es de forma centralizada.

La manera en la que los gobiernos nacionales pueden contribuir al robustecimiento de las prácticas participativas de gestión presupuestaria es incentivándolas, estimulándolas y hasta apoyándolas de distintas formas, como por ejemplo, con formación. El acceso a fondos especiales y/o a beneficios de políticas públicas nacionales puede concederse a los gobiernos locales que practiquen la gestión presupuestaria participativa como otra forma de incentivo. Actuando así, los gobiernos nacionales podrán, dentro de un proyecto a largo plazo, adoptar la participación ciudadana en la definición de presupuestos sectoriales nacionales (salud, educación, transporte etc.), contando con la experiencia consolidada de experiencias participativas locales previamente incentivadas. El ciudadano que se formó en la tradición participativa local será una pieza importante en las experiencias de los niveles superiores de gobierno.

Hay que considerar también el caso de los gobiernos unitarios; ellos son los responsables de lo que en los gobiernos federales les corresponde a los gobiernos de los estados, inexistentes para ellos. Por tanto, los Presupuestos Participativos, en estos gobiernos unitarios, tienen que ser, necesariamente nacionales, a pesar de ocuparse también de políticas públicas de naturaleza y alcance local (minimamente). En conclusión, la naturaleza predominantemente local del Presupuesto Participativo se debe mucho más a la viabilidad de la participación ciudadana en asuntos de naturaleza local, que del nivel en las escalas geográficas y políticas en que se encuentra el gobierno que lo practica.

\subsection{Tipología de Presupuesto Participativo en lo que respecta a} la fuente de poder que lo propone o impone: gobierno nacional, del estado, local, grupo de la sociedad civil local, agencia de desarrollo o financiación

Las experiencias de Presupuesto Participativo pueden tener distintos orígenes en lo referente a los actores o instituciones que las proponen o las hacen obligatorias. Esas circunstancias dan oportunidad para otra tipología de Presupuesto Participativo.

El Presupuesto Participativo puede ser propuesto e implementado por ejecutivos locales interesados en un tipo renovado de relación Estado-sociedad civil, siendo la población llamada a participar de diversas maneras, con distintos niveles de autonomía. También varían, en los esfuerzos para instaurar una nueva forma de relación entre el Estado y la sociedad civil, las motivaciones político- 
ideológicas. Esos motivos, así como las formas de solucionarlos sólo se pueden comprender mediante el análisis detallado de cada caso, aunque puede haber grupos de casos con motivaciones y metodologías muy semejantes, debido al liderazgo de un determinado grupo político. El caso de las experiencias petistas locales en Brasil ilustra muy bien este tipo de situaciones: el Presupuesto Participativo formaba parte del «modo petista de gobernar».

La iniciativa de Presupuesto Participativo puede también partir del Poder Legislativo, que obliga al Ejecutivo por medio de ley a poner en marcha mecanismos de interlocución con la población para elaborar la pieza presupuestaria. El Legislativo puede además promover, el mismo, audiencias públicas sobre el presupuesto. En el primer caso, el legislador estará forzando el Presupuesto Participativo en la fase de elaboración; en el segundo, en la fase de discusión y deliberación.

Nada impide que grupos organizados de la sociedad civil, asociaciones de vecinos, organizaciones no-gubernamentales ${ }^{18}$, sindicatos o grupos profesionales (economistas, abogados etc. $)^{19}$, propongan la puesta en marcha del Presupuesto Participativo, sea sugiriéndoselo al Ejecutivo y/o al Legislativo, sea desarrollando autónomamente reuniones de discusión con la población.

Existen también casos de Presupuesto Participativo que son propuestos, cuando no exigidos, por agencias de desarrollo y financiación, que tienen como objetivo mayor transparencia en el uso de los recursos que ponen a disposición de determinados gobiernos. Ilustra esta situación los casos de Presupuesto Participativo en Guatemala y Bolivia, a los que de alguna forma fueron obligados para que pudieran acceder al perdón de la deuda propiciada por los fondos HIPC II - Heavily Indebeted Poor Countries II (GolDFRANK, 2003).

El Presupuesto Participativo puede ser también obligatorio para los gobiernos locales por una ley nacional, como en el caso de Perú (GolDFRANK, 2003). El problema de este modelo de Presupuesto Participativo es la distancia que suele haber entre la voluntad del legislador y del gobierno nacional para que se de la participación vis-a-vis con la voluntad de los responsables de la implementación del Presupuesto Participativo en los gobiernos locales. Obligatorio, el Presupuesto Participativo se puede transformar en simple obediencia a la ley, entonces queda su contenido vacío y sus perspectivas disminuidas.

De acuerdo con el criterio de la fuente de voluntad o poder para iniciar y poner en marcha el Presupuesto Participativo, se observa que existen las siguientes posibilidades. Primera, los Presupuestos Participativos opcionales

18 En el Reino Unido son las ONGs Community Pride Initiative y Oxfam los que han puesto en marcha las experiencias de Presupuesto Participativo.

19 Los primeros promotores de los presupuestos participativos en Alemania fueron fundaciones cívicas que trabajan ya en la modernización de las instituciones, como el Instituto de Investigación de la Asociación de Municipios (KGSt) o las fundaciones Bertelsmann y Hans Böcker de la confederación de los sindicatos. 
(generalmente propuestos a los gobiernos por grupos organizados de la sociedad civil, pudiendo o no ser acatados y, si lo fueran, asimilando total o parcialmente los modelos propuestos) y los Presupuestos Participativos obligatorios (convertidos en obligatorios por ley). En esta segunda hipótesis, puede tratarse de ley local o nacional que obliga a los poderes locales. Existe también el Presupuesto Participativo inducido, que es implementado no por voluntad popular o iniciativa gubernamental autónomas, sino por el impulso de la intervención externa (agencias de desarrollo o financiación). Cada situación tiene sus propios puntos fuertes y débiles. La sustentabilidad es uno de los factores distintivos más importantes. Si los Presupuestos Participativos obligados por ley están garantizados en cuanto a los acontecimientos, no lo están en calidad y efectividad de las prácticas. Si los Presupuestos Participativos espontáneos son más efectivos, no están, por contra, asegurados a lo largo del tiempo, dependiendo a veces de entusiasmos pasajeros. Los Presupuestos Participativos inducidos se benefician del efecto catalizador de los agentes externos, pero una vez que estos agentes se retiran, la experiencia puede decaer y desaparecer. En cuanto que la espontaneidad refuerza la intensidad de las experiencias de Presupuesto Participativo, la obligatoriedad refuerza la extensión cronológica. Combinar ambos los fortalece, siendo un gran desafío práctico.

\subsection{Tipología de Presupuesto Participativo según los criterios para la habilitación de los participantes}

La participación ciudadana en el proceso presupuestario debe ser ampliamente garantizada, para que los resultados sean válidos y legítimos, pues de lo contrario la contribución a la profundización de la democracia y a la intensificación del peso de la voluntad popular en la elección de prioridades se diluye y puede hasta desaparecer. También debe ser regulada, ya sea por ley, ya por medio de reglamentos internos decididos previamente por los propios participantes. Existen varios criterios que pueden ser utilizados para propiciar la participación.

La participación puede ser aceptada a partir de la condición de elector del individuo (lo que requiere una edad mínima de acuerdo con la legislación electoral). De ese modo, cada uno puede ejercer su derecho a opinar, por ejemplo, con respecto a las prioridades indicadas para atender necesidades de toda la ciudad.

La condición de vecino, en edad electoral o cercana a ella ${ }^{20}$, puede ser aceptada para participar en la elección de prioridades regionales. La comprobación de la residencia puede ser exigida, para evitar interferencias externas ${ }^{21}$.

\footnotetext{
20 En muchas de las experiencias europeas la edad para participar en los presupuestos participativos es de 16 años.

21 También en algunos casos se permite la participación a los que trabajan en el municipio.
} 
Se puede, también, exigir que la participación sea respaldada por mandato cedido por una organización, de carácter territorial (asociación de vecinos, por ejemplo) o temático (sociedad deportiva o cultural, por ejemplo). En ese caso, la amplitud de la participación disminuye.

Teniendo en cuenta que el proceso de participación se puede dar en varias reuniones, es posible combinar la condición individual y la de representante en función de ellas. Así, en el momento de escoger las prioridades de cada barrio o región, todos los vecinos pueden participar y son llamados a escoger también a sus representantes en las fases posteriores, los cuales, a partir de entonces tendrán la condición de delegados. Democracia directa y representativa pueden combinarse de diversas maneras.

Un problema que puede producirse en esa combinación es el de la asimilación del proceso participativo por la burocracia representativa interna del gobierno. En Recife, en el Estado brasileño de Pernambuco se dio eso. Según SiLVA (2003, pág. 316), en el período 1993-96 se llego a aceptar la participación solamente de delegados escogidos por asociaciones previamente registradas en el ayuntamiento.

\subsection{Tipología del Presupuesto Participativo con base regional o temática}

Originalmente el Presupuesto Participativo se basó en la definición de prioridades de acuerdo con criterios regionales. Las ciudades eran divididas en grupos de barrios (regiones y sub-regiones), realizando cada una sus encuentros y reuniones para la elección de obras y servicios, nombrando delegados para las fases siguientes y para la composición del consejo del presupuesto participativo. Posteriormente se pasó a adoptar también el criterio temático (salud, educación, seguridad pública, empleo y renta etc.). Muchos consideran que ése fue un paso importante porque redujo el peso y relativizó la importancia excesiva de las reivindicaciones realizadas exclusivamente con base en carencias detectadas a partir del lugar donde se vive («corporativismo de barrio») ${ }^{22}$. Con el paso del tiempo, la combinación de los dos espacios pasa a ser bastante aceptado, sobre todo en Brasil, pero no sin traer consigo complicaciones a consecuencia de la participación de públicos muy diferentes (en formación y demandas) y de la necesidad de compatibilizar criterios muy heterogéneos para llegar finalmente a las prioridades presupuestarias.

Una última clasificación es la que considera grupos específicos de personas o segmentos de población. Surgen entonces las propuestas de Presupuesto Par-

22 En las experiencias francesas la vinculación del debate con las decisiones públicas a nivel de ciudad no existe. 
ticipativo de niños ${ }^{23}$, Presupuesto Participativo de jóvenes, Presupuesto Participativo de mujer etc.

Se llega, pues, a una tipología que contempla las siguientes posibilidades: Presupuesto Participativo territorial, temático y para grupos específicos. Todas las combinaciones son posibles.

\subsection{Tipología de Presupuesto Participativo según las formas de participación: investigaciones y encuestas, reuniones y asambleas presénciales o a través de canales virtuales}

La realización de investigaciones y encuestas para conocer la opinión de la población sobre las prioridades presupuestarias no deja de ser un tipo de Presupuesto Participativo ${ }^{24}$, a pesar de darle mayor valor al debate mediante la realización de reuniones y asambleas. Éstas, a su vez, pueden ser realizadas con medios tecnológicos que permiten hablar del Presupuesto Participativo virtual $^{25}$. Cada uno tiene sus ventajas e inconvenientes. Y todas ellas pueden ser aprovechadas para ampliar la calidad del proceso participativo. Las encuestas e investigaciones pueden ser divulgadas para apoyar y cuestionar las opiniones particulares de los actores, del gobierno o de la población; los mecanismos de participación virtual pueden contribuir a atraer un tipo de público poco acostumbrado a las asambleas presenciales; pero a pesar de todo las reuniones y las asambleas deben seguir siendo importantes en el Presupuesto Participativo. Pueden ser deliberativas, mientras que las otras formas de participación, por ejemplo, pueden ser consultivas. O de otro modo, ciertas prioridades pueden ser definidas por medio de investigaciones, otras por encuentros virtuales y otras por encuentros presénciales. Al final es posible compatibilizar todas las formas.

\subsection{Tipología de Presupuesto Participativo según las formas de regulación del proceso}

El Presupuesto Participativo puede tener sus estructuras y procesos regulados por ley o por reglamentos internos discutidos de común acuerdo entre los participantes, procedentes del gobierno y de la sociedad civil. Como ocurre con frecuencia, cada alternativa tiene límites y potencialidades distintos, sien-

\footnotetext{
23 En España existen cada vez más experiencias de Presupuesto Participativo de niños en lugares donde ya habían comenzado experiencias con adultos con mucho éxito.

24 Es una forma muy utilizada en países como Gran Bretaña o Portugal.

25 En Getafe (España) han puesto en marcha este año en un distrito del municipio (Sector III- Cerro Buenavista) una experiencia pionera para poder votar los vecinos las propuestas presentadas en la asamblea vecinal mediante internet.
} 
do conveniente la adopción de una metodología híbrida. La obligatoriedad de la participación, la periodicidad y los plazos, las obligaciones del gobierno y de los participantes, cosas de ese tipo pueden ser definidas por ley. Para otras cuestiones, como la composición de los consejos, los procedimientos para la elección de delegados o los criterios para el establecimiento de prioridades etc, la ley puede remitir a los reglamentos internos decididos anualmente por instancias colectivamente definidas. Cuestiones de principios, más rígidas, deben ser sometidas a la decisión legislativa; otras, relativas a procesos que se van perfeccionando a lo largo del tiempo, se deben dejar para formas más flexibles de regulación, como los reglamentos internos, que deben ser revisados cada año, teniendo en cuenta la experiencia anterior y la correlación de fuerzas existentes.

\subsection{Tipología de Presupuesto Participativo según de donde provenga la iniciativa de presentación de propuestas}

La presentación de propuestas para la deliberación en el proceso presupuestario participativo puede provenir de la población, del gobierno o de ambos.

Cuando la iniciativa es del gobierno, éste puede presentar una propuesta completa, con todos los programas y proyectos, y someterla a debate o, alternativamente, puede discutir con la población para recoger elementos con los que después elaborar su propuesta completa. También es posible una combinación de procedimientos.

Cuando la iniciativa es de la población, la fragmentación es inevitable, entonces es necesario un esfuerzo de síntesis y mayor compatibilidad. La falta de visión de conjunto de los problemas es la causa de esa fragmentación. El gobierno puede definir a priori algunas áreas en las cuales las propuestas de la población pueden incluirse, evitando así la dispersión.

Es posible adoptar una metodología en la que la iniciativa de la población y la del gobierno ocurran paralelamente con momentos de discusión para hacerlos compatibles. Por ejemplo, la población discute en reuniones temáticas las prioridades sobre salud pública. Mientras tanto, el área de salud del gobierno elabora su propuesta para el presupuesto basada en sus diagnósticos técnicos y políticos. Los dos conjuntos de propuestas y reivindicaciones son comparados, separando las cuestiones en las que hay convergencia de las que hay divergencia. Los temas convergentes no exigen discusión, debiendo canalizarse el esfuerzo hacia el debate de los temas divergentes. Resueltas las divergencias, el gobierno elabora su presupuesto de salud, haciendo lo mismo con otras políticas públicas. Después reúne todos los presupuestos parciales y constata, necesariamente, que las demandas son muy superiores a la capacidad de financiación existente. Empiezan entonces los recortes, éstos pueden hacerse por el propio gobierno que llega a una propuesta presupuestaria que discutirá con la 
población en reuniones y asambleas. O puede optar por hacer primero las reuniones y asambleas para realizar luego los recortes.

\section{CONCLUSIÓN}

El Presupuesto Participativo, después de casi veinte años de experimentación en varios municipios, de prácticamente todos los continentes, se presenta como una buena metodología de gestión presupuestaria para la obtención de políticas públicas más eficientes, eficaces y efectivas y también para la profundización de las relaciones democráticas. Su potencialidad para contribuir a cambios importantes en la relación Estado-sociedad es aplaudida por actores políticos del más amplio espectro político-ideológicos. Su adopción ha sido defendida por diferentes partidos y gobiernos e incentivada por organizaciones no-gubernamentales e instituciones multilaterales de desarrollo y financiación.

En la práctica, mientras tanto, el Presupuesto Participativo se enfrenta a innumerables obstáculos que dificultan enormemente la sostenibilidad de las experiencias iniciadas. Hasta una de las más antiguas, la de Porto Alegre, en el Estado brasileño do Rio Grande do Sul, iniciada en 1989, pasa hoy por una fase en la que se cuestiona su continuidad. El cambio de procedimientos, la redefinición de papeles, la alteración de la lógica de los procesos deliberativos y otras innovaciones que suelen ocurrir de acuerdo a la correlación de fuerzas predominante en cada coyuntura, lleva a que los grupos que pierden la hegemonía en el Presupuesto Participativo pasen a negar su existencia. En el interior de esa lucha por el predominio de modelos específicos e históricamente determinados de Presupuesto Participativo, comienzan a colisionar diferentes definiciones de la metodología que terminan confundiendo a los interesados en la emergencia de nuevas experiencias de Presupuesto Participativo que no tengan o no estén tomando parte en las disputas existentes sobre casos concretos de Presupuesto Participativo.

A fin de definir ese problema concreto, que puede convertirse en un obstáculo insalvable para el progreso del Presupuesto Participativo, impidiendo que materialice toda su potencialidad en diferentes lugares de todo el mundo, es fundamental enfrentar la cuestión clave de la definición de lo que es el Presupuesto Participativo.

Un esfuerzo analítico para contribuir a ello, basado en la observación de las experiencias y en la reflexión sobre ellas, y tomando como punto de partida la defensa de la continuidad y la profundización del Presupuesto Participativo como elemento renovador de las relaciones Estado-sociedad, nos lleva a concluir que no es posible una definición a-histórica del Presupuesto Participativo. De hecho el Presupuesto Participativo es el resultado de un proceso histórico de innovación institucional en el interior de una fase específica del desarrollo so- 
cioeconómico en el que, nuevamente, el Estado está en discusión. En el interior de ese debate, que incluye gobiernos locales, intermedios y nacionales que están en distintos niveles de desarrollo, asumiendo en ellos el Estado diferentes funciones y con desiguales capacidades de actuación y financiación, el Presupuesto Participativo aparece como una metodología cada vez más considerada, pero cuyas formas dependen de las circunstancias en las que se materializa. Siendo así, una definición a priori del Presupuesto Participativo no es conveniente para su progreso, ya que lo que algunos llamaran Presupuesto Participativo será negado por otros, según las diferentes concepciones y objetivos adoptados por los competidores.

Para solucionar este problema, pero sin negar la existencia de diferentes razones político-ideológicas para defender o atacar el Presupuesto Participativo, se pueden usar varias tipologías de Presupuesto Participativo que permiten caracterizar y clasificar las experiencias concretas, adjetivándolas de acuerdo con sus fundamentos y evolución histórica.

La tabla siguiente sintetiza los elementos que fundamentan las tipologías presentadas a lo largo de este trabajo.

Se espera que las tipologías propuestas contribuyan al avance de las investigaciones sobre Presupuesto Participativo, en la medida en que rompen el obstáculo hoy existente para realizar un mapa y clasificar los casos existentes (como se aprecia en SHAH, 2003 y RibeIRO E GRAZIA, 2003). Si partimos de definiciones restrictivas o demasiado amplias, la investigación de experiencias presenta dificultades para la inclusión o exclusión de casos concretos. Haciendo uso de las tipologías todos los casos pueden ser debidamente encuadrados y comparados entre si.

También pueden contribuir a la diseminación de las prácticas de Presupuesto Participativo, pues ayudan a urdir tácticas y estrategias de acción para iniciarlas y mantenerlas con claridad frente a los desarrollos posibles y las negociaciones necesarias para permitir la participación de corrientes políticas e ideológicas enfrentadas. La percepción del carácter contradictorio de todo proceso de cambio, juntamente con la delimitación de las posibilidades que presenta, es fundamental para el éxito del comportamiento de actores y agentes que se guían por el respeto a la democracia en el intento de aumentar las prácticas de Presupuesto Participativo.

Lo que garantiza el contenido democratizante y eficiente de un caso concreto de Presupuesto Participativo no es su definición a priori, sino la búsqueda sistemática y persistente de cualificación de la metodología y de los procedimientos utilizados en la práctica, a lo largo del tiempo. En la medida en que esa metodología y esos procedimientos van mejorando, a base de avances y retrocesos según la lucha política cotidiana, la definición adjetivada especifica del 
REALA 308 (SEPTIEMBRE-DICIEMBRE, 2008)

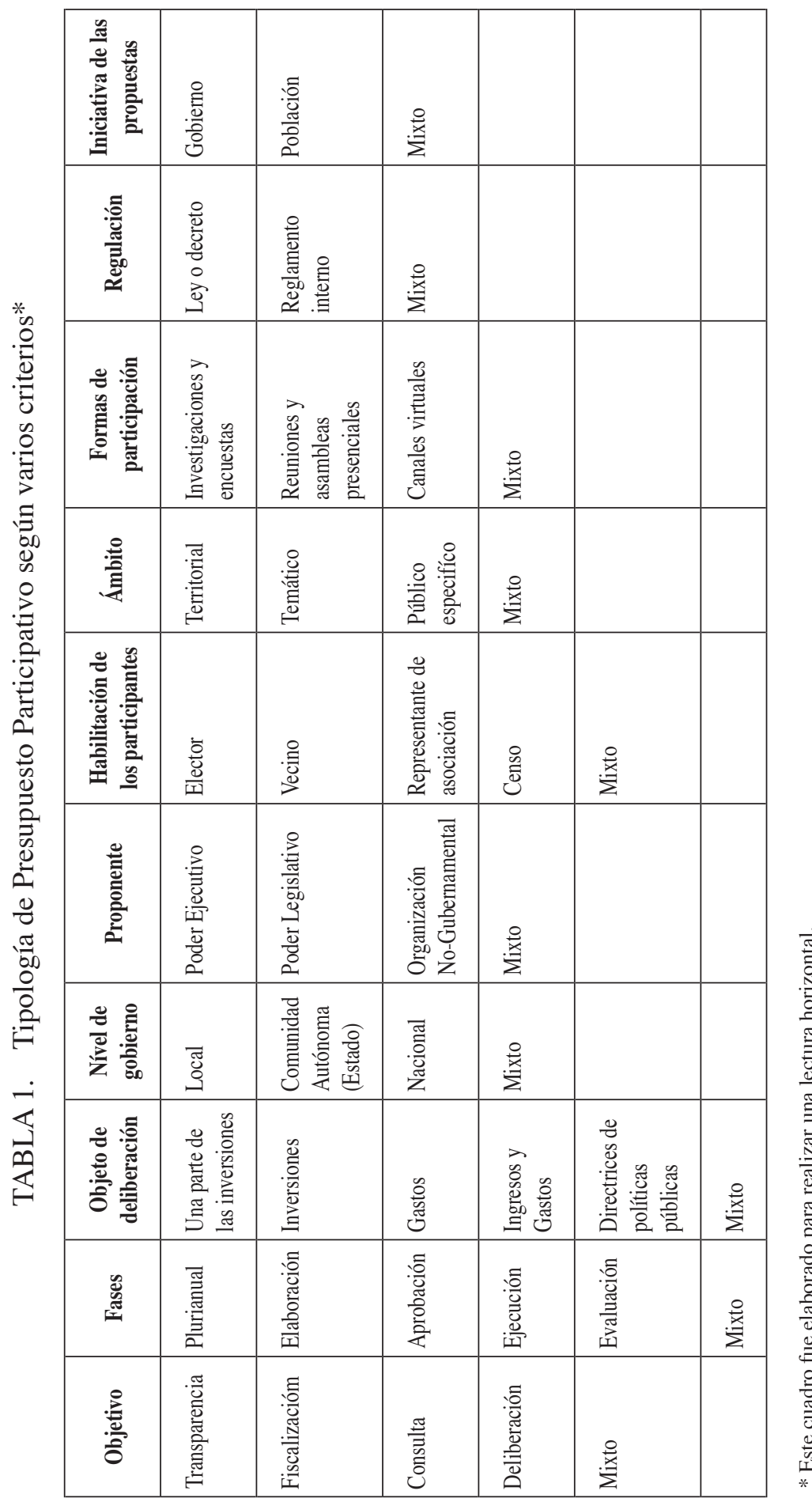


Presupuesto Participativo, a partir de las tipologías aquí presentadas, va surgiendo como resultado de un proceso histórico de innovación institucional.

Estas tipologías contemplan aspectos esenciales del Presupuesto Participativo, pero no agotan todas las posibilidades. Tampoco son perfectas e incuestionables, debiendo ser objeto de constante mejora, a la luz de nuevas reflexiones y observaciones, respaldadas por las prácticas.

Por último, señalar que una definición de Presupuesto Participativo que considere lo expuesto en este articulo debe considerarla como una metodología de gestión presupuestaria local o nacional, en la que ciudadanos que no ocupan cargos electos en el gobierno tienen la oportunidad de discutir, de forma sistemática y abierta, entre si y con los gobernantes y administradores públicos, por lo menos una parte de las decisiones de gasto público (por lo menos las inversiones), con o sin poder de deliberación, siendo esta última una condición que lleva al Presupuesto Participativo a su grado máximo de innovación. No siendo deliberativo, el Presupuesto Participativo es válido, cumpliendo un papel importante para la transparencia, la responsabilidad y la calidad de la gobernanza pública. Manteniendo algún grado de participación de los ciudadanos y tratando asuntos presupuestarios, cualquier experiencia puede ser denominada Presupuesto Participativo desde el momento, independientemente de quien la inicie y coordine, de la forma como se organice y regule, en que tenga algún impacto innovador sobre la gestión de los recursos financieros y/o sobre la relación gobierno-sociedad en lo relacionado con las decisiones presupuestarias. No existiendo una metodología única de Presupuesto Participativo, hay que concebirla siempre como un proceso que se ajusta caso a caso, de acuerdo a las realidades en las que ocurre, la coyuntura económica y política y los intereses en juego. La propia definición del Presupuesto Participativo puede ser un elemento de disputa en el proceso, ya que las experiencias pueden ponerse en marcha por diversas razones u objetivos, no siempre consensuados. Una de las características fundamentales del Presupuesto Participativo es la tensión que los ingredientes de democracia directa que lo configuran genera en el interior de las prácticas convencionales de la democracia representativa, cuyos limites el Presupuesto Participativo cuestiona sin, todavía, negar la importancia de la representación.

\section{BIBLIOGRAFÍA}

Alves, Márcio Moreira (1980). A força do povo - democracia participativa em Lajes. São Paulo: Brasiliense.

AVRITZER, Leonardo (2002). New Public Spheres in Brazil: Local Democracy and DeliberativePolitics. http://www.democraciaparticipativa.org/files/LeonardoAvritzer-NewPublicSpheresinBrazil.pdf.

AVRITZER, Leonardo e NAVARRO, Zander (2003). A inovação democrática no Brasil: o orçamento participativo. São Paulo: Cortez Editora. 
AVRITZER, Leonardo (2003). O Orçamento Participativo e a teoria democrática: um balanço crítico. In: Avritzer, Leonardo e Navarro, Zander (2003). A inovação democrática no Brasil: o orçamento participativo. São Paulo: Cortez Editora, págs. 11-60., o petista de governar. São Paulo: Partido dos Trabalhadores/Diretório Regional de São Paulo e Secretaria Nacional de Assuntos Institucionais-Caderno Especial de Teoria \& Debate.

Bossols, Irene L. (1987). A formulação democrática do orçamento municipal - A experiência de Vila Velha, ES, no período 1983-86. Revista de Administração Municipal, v. 34, n. 184, págs. 6-11, jul-set.

BRESSER-PEREIRA, Luiz Carlos; WILHEIM, Jorge e SolA, Lourdes (Org.) (1996). Sociedade e Estado em transformação. Brasília: ENAP, São Paulo: Imprensa Oficial/Ed. UNESP.

Brillantes Jr., Alex, B. (2007). The Philippines: Civic Participation in Local Governance - Focus on Subnational Budgeting and Planning. In: SHAH, Anwar (Ed.) (2007). Participatory Budgeting. Public Sector Governance and Accountability Series. Washington D.C.: The World Bank. CD ROM.

Bonduki, Nabil (Org.) (1996). Habitat - As práticas bem-sucedidas em habitação, meio ambiente e gestão urbana nas cidades brasileiras. São Paulo: Studio Nobel.

CARneIRO, Dirceu (1984). Lajes, a força do povo. In: HERRMANn NeTO, João (Org.) (1984). Democracia feita em casa. Brasília: Câmara dos Deputados - Coord. de Publicações, págs. 69-83.

COVRE, Amaro (1984). Experiência de planejamento participativo em Boa Esperança ES. In: HerRmann Neto, João (Org.) (1984). Democracia feita em casa. Brasília: Câmara dos Deputados - Coord. de Publicações, págs. 59-67.

DAGNINO, Evelina (1997). Os movimentos sociais e a emergência de uma nova noção de cidadania. In: Dagnino, Evelina (Org.). Os anos 90: política e sociedade no Brasil. São Paulo: Ed. Brasiliense.

FARIAS, Cláudia Feres (2003). Do conflito jurídico ao consenso democrático: uma versão da implementação do OP-RS. In: AVRITZER, Leonardo e NAVARRo, Zander (2003). A inovação democrática no Brasil: o orçamento participativo. São Paulo: Cortez Editora, págs. 217-247.

Ferlie, Ewan; Asburner, Lynn; FitzGerald, Louise e Petigrew, Andrew (1996). A nova administração pública em ação. Brasília: Ed. UnB/ENAP, 1999.

Föscher, Alta (2007). Participatory Budgeting in Central and Eastern Europe. In: SHAH, Anwar (Ed.) (2007). Participatory Budgeting. Public Sector Governance and Accountability Series. Washington D.C.: The World Bank, págs. 127-156.

FöschER, Alta (2007). Participatory Budgeting in Asia. In: SHAH, Anwar (Ed.) (2007). Participatory Budgeting. Public Sector Governance and Accountability Series. Washington D.C.: The World Bank, págs. 157-189.

FösCHER, Alta (2007) Participatory Budgeting in the Middle East and North Africa. In: Shah, Anwar (Ed.) (2007). Participatory Budgeting. Public Sector Governance and Accountability Series. Washington D.C.: The World Bank, págs. 225-241.

GANUZA FERNÁNDEZ, Ernesto y GómEZ FORTES, Braulio (2008): «Control político y participación en democracia: los presupuestos participativos», Estudio de Progreso 38/2008, Fundación Alternativas, Madrid.

GANUZA FERNÁNDEZ, Ernesto (2007): «Tipología y modelos de los presupuestos participativos en España», Documentos de Trabajo 1307, Instituto de Estudios Sociales Avanzados, Córdoba. 
GECD - Grupo de Estudos sobre a Construção Democrática/UNICAMP - Universidade Estadual de Campinas/a (1998/1999). Dossiê «Os movimento sociais e a construção democrática». Idéias, ano 5/6, vol. 5, n. ${ }^{\circ}$ 2/vol. 6, n. ${ }^{\circ} 1$, págs. 5-122.

GECD - Grupo de Estudos sobre a Construção Democrática/UNICAMP - Universidade Estadual de Campinas/b (1998/1999). Esfera pública e democracia no Brasil. In: GECD - Grupo de Estudos sobre a Construção Democrática/UNICAMP - Universidade Estadual de Campinas/a (1998/1999). Dossiê «Os movimento sociais e a construção democrática». Idéias, ano 5/6, vol. 5 , n. ${ }^{\circ}$ 2/vol. 6, n. $^{\circ} 1$, págs. 44-74.

GECD - Grupo de Estudos sobre a Construção Democrática/UNICAMP - Universidade Estadual de Campinas/c (1998/1999). Sociedade civil e democracia: reflexões sobre a realidade brasileira. In: GECD - Grupo de Estudos sobre a Construção Democrática/UNICAMP - Universidade Estadual de Campinas/a (1998/1999). Dossiê «Os movimento sociais e a construção democrática». Idéias, ano 5/6, vol. 5, n. ${ }^{\circ}$ 2/vol. 6 , n. ${ }^{\circ}$ 1, págs. 13-42.

GenRo, Tarso e SouZA, Ubiratan (1997). Orçamento participativo: a experiência de Porto Alegre. 2a e. São Paulo: Fundação Perseu Abramo.

GoHn, Maria da Glória (1993). Movimentos, organizações populares e cidadania: conquistas, problemas e perspectivas nos anos 90. Anais do XVII Encontro da ANPOCS - Associação Nacional de Pós-Graduação em Ciências Sociais.

GoldFRANK, Benjamin (2007). Lessons from Latin America's Experience with Participatory Budgeting. In: SHAH, Anwar (Ed.). Participatori budgeting. Public Sector Governance and Accountability Series Washington DC: The World Bank, págs. 91-126.

Herrmann Neto, João. Administração municipal de Piracicaba: a serviço de quem? In: Herrmann Neto, João (Org.) (1984). Democracia feita em casa. Brasília: Câmara dos Deputados - Coord. de Publicações, págs. 85-92.

Krylova, Elena (2007). Russia: Civic Participation in Subnational Budgeting. In: SHAH, Anwar (Ed.) (2007). Participatory Budgeting. Public Sector Governance and Accountability Series. Washington D.C.: The World Bank. CD ROM.

Krylova, Elena (2007). Ukrayne: Civic Participation in Subnational Budgeting. In: SHAH, Anwar (Ed.) (2007). Participatory Budgeting. Public Sector Governance and Accountability Series. Washington D.C.: The World Bank. CD ROM.

Musgrave, Richard A. \& Musgrave, Peggy B. (1976). Finanças Públicas - Teoria e Prática. São Paulo: Ed. Campus, 1980.

NAVARro, Clemente J. (2008): «Los rendimientos de los mecanismos de participación: propuesta de sistema de evaluación y aplicación al caso de los Presupuestos Participativos», Revista del CLAD Reforma y Democracia $n .^{\circ} 40$, febrero, pp. 81-102.

PAUL, Samuel (2007). India: Civic Participation in Subnational Budgeting. In: SHAH, Anwar (Ed.) (2007). Participatory Budgeting. Public Sector Governance and Accountability Series. Washington D.C.: The World Bank. CD ROM.

PessoA, Enildo (1988). Planificação: a opção pelas classes populares. Campinas: Papirus.

PIRES, Valdemir (1999; 2001). Orçamento participativo: o que é, para que serve, como se faz. Piracicaba: edição do autor; Barueri: Manole.

PIRES, Valdemir y PinedA, Carmen (2008). Formación y preparación de los actores del Presupuesto Participativo. Revista de Estudios Locales n. ${ }^{\circ} 113$. Madrid.

Rhaman, Atiur; KABIR, Mahfuz; RAZZAQue, Mohammad (2007). Bangladesh: Civic Participation in Subnational Budgeting. In: SHAH, Anwar (Ed.) (2007). Participatory Budgeting. 
Public Sector Governance and Accountability Series. Washington D.C.: The World Bank. CD ROM.

Ribeiro, Ana Clara Torres e GraZIA de Grazia (2003). Experiências de Orçamento Participativo no Brasil - Período de 1997 a 2000. Petrópolis: Ed. Vozes.

SADER, Eder (1988). Quando novos personagens entram em cena. Rio de Janeiro: Paz e Terra.

SANTOS, Boaventura de Souza (1998). Budgetings in Porto Alegre: Towards a Redistributive Democracy. Politics and Society, v. 26, n. ${ }^{\circ}$, págs. 461-510.

SHAH, Anwar (Ed.) (2007). Participatory Budgeting. Public Sector Governance and Accountability Series. Washington D.C.: The World Bank.

SHALl, Adrienne (2007). Sub-Saharan Africa's Experience with Participatory Budgeting. In: SHAH, Anwar (Ed.) (2007). Participatory Budgeting. Public Sector Governance and Accountability Series. Washington D.C.: The World Bank, págs. 191-223.

Shall, Adrienne (2007) South Africa: Civic Participation in Local Government Policy Making and Budget Process. In: SHAH, Anwar (Ed.) (2007). Participatory Budgeting. Public Sector Governance and Accountability Series. Washington D.C.: The World Bank. CD ROM.

SILVA, Tarcisio da (2003). Da participação que temos à que queremos: processo do Orçamento Participativo na cidade do Recife. In: Avritzer, Leonardo e NAVARro, Zander (2003). A inovação democrática no Brasil: o orçamento participativo. São Paulo: Cortez Editora, págs. 297-334.

Sintomer, Y., et al. (2006), Participatory Budgets in an European Comparative Approach. Volume I, Centre MarcBloch/Hans-Böckler-Stiftung/Humboldt-Universität, Berlin, 2006.

Suwanmala, Charas (2007). Thailand: Civic Participation in Subnational Budgeting. In: SHAH, Anwar (Ed.) (2007). Participatory Budgeting. Public Sector Governance and Accountability Series. Washington D.C.: The World Bank. CD ROM. 